\title{
Sentiment and Momentum
}

\author{
Constantinos Antoniou \\ John A. Doukas \\ Avanidhar Subrahmanyam
}

This version: May 20, 2011

\begin{abstract}
This paper sheds empirical light on whether sentiment affects the profitability of price momentum strategies. We hypothesize that news that contradicts investors' sentiment causes cognitive dissonance, which slows the diffusion of signals that oppose the direction of sentiment. This phenomenon tends to cause underpricing of losers under optimism and underpricing of winners under pessimism. While the latter phenomenon can be corrected by arbitrage buying, short-selling constraints impede arbitraging of losers under optimism, causing momentum to be stronger in optimistic periods. Our empirical analysis supports this argument by showing that momentum profits arise only under optimism, and are driven principally by strong momentum in losing stocks. This result survives a host of robustness checks including controls for market returns, firm size and analyst following. An analysis of net order flows from small and large trades indicates that small (but not large) investors are slow to sell losers during optimistic periods. Momentum-based hedge portfolios formed during optimistic periods experience longrun reversals.

Antoniou is from XFI Centre for Finance and Investment, University of Exeter. Doukas is from Old Dominion University and Judge Business School, University of Cambridge. Subrahmanyam is from the Anderson School, University of California, Los Angeles. Address correspondence to A. Subrahmanyam, The Anderson School at UCLA, Los Angeles, CA 90095-1481, email: subra@anderson.ucla.edu, phone (310) 825-5355. We thank an anonymous referee, Hank Bessembinder (the editor), Sridhar Arcot, Werner DeBondt, Andras Fulop, Stuart Gabriel, Soeren Hvidkjaer, Murali Jagannathan, Dennis Lasser, Ken Lehn, Laurence Lescourret, Haim Levy, Yee Cheng Loon, Hanno Lustig, Marios Panayides, Richard Roll, Kristian Rydqvist, Steve Salterio, Eduardo Schwartz, Carmen Stefanescu, Geoff Tate, Shawn Thomas, Premal Vora, Neng Wang, and seminar participants at ESSEC, University of Pittsburgh, UCLA, Indira Gandhi Institute of Development Research, Indian Institute of Management (Kolkata), SUNYBinghamton, and the 2010 Asian Finance Conference in Hong Kong, as well as the Second Annual Research Symposium on Current Issues in Accounting and Finance at Brock University, for valuable comments, and the Conference Board for kindly providing us with the sentiment data. We also are grateful to Jeffrey Wurgler and Malcolm Baker for making their sentiment index publicly available.
\end{abstract}




\title{
Sentiment and Momentum
}

\begin{abstract}
This paper sheds empirical light on whether sentiment affects the profitability of price momentum strategies. We hypothesize that news that contradicts investors' sentiment causes cognitive dissonance, which slows the diffusion of signals that oppose the direction of sentiment. This phenomenon tends to cause underpricing of losers under optimism and underpricing of winners under pessimism. While the latter phenomenon can be corrected by arbitrage buying, short-selling constraints impede arbitraging of losers under optimism, causing momentum to be stronger in optimistic periods. Our empirical analysis supports this argument by showing that momentum profits arise only under optimism, and are driven principally by strong momentum in losing stocks. This result survives a host of robustness checks including controls for market returns, firm size and analyst following. An analysis of net order flows from small and large trades indicates that small (but not large) investors are slow to sell losers during optimistic periods. Momentum-based hedge portfolios formed during optimistic periods experience longrun reversals.
\end{abstract}




\section{Introduction}

Does sentiment affect financial asset prices? This issue is enduring and has taken on renewed significance in the context of dramatic rises and falls in the stock market during this decade. We address this question by examining whether variations in profitability from a key pattern in stock prices, namely, stock price momentum, can be explained by variations in sentiment. Notably, our sentiment proxy is measured outside of the financial markets, as we use the Consumer Confidence Index ${ }^{\circledR}$ published by the Conference Board (CB) (orthogonalized with respect to a set macroeconomic variables).

The phenomenon of price momentum has been documented in several studies [e.g., Jegadeesh and Titman (1993, 2001); Chan, Jegadeesh, and Lakonishok (1996)] and is well known to survive consideration of standard risk adjustments [Fama and French (1996)]. This return pattern is found to be robust across different markets [Rouwenhorst (1999); Doukas and McKnight (2002)] and different asset classes [Asness, Moskowitz, and Pedersen (2008)]. The highly debated explanations for price momentum range from time-varying expected returns [e.g., Johnson (2002)] to rationales based on market frictions and investor psychology [Hong and Stein (1999); Daniel, Hirshleifer, and Subrahmanyam (1998)]. ${ }^{1}$ We shed light on the latter class of arguments by examining the relationship between momentum-induced profits and sentiment.

Sentiment, broadly defined, refers to whether an individual, for whatever extraneous reason, feels excessively optimistic or pessimistic about a situation. A large body of the psychology literature finds that peoples' current sentiment affects their judgment of future events. For example, Johnson and Tversky (1983) show that people that read sad newspaper articles subsequently view various causes of death, such as disease etc., as more likely than people who read pleasant newspaper articles. In general, the evidence indicates that people with positive sentiment make optimistic judgments and choices, whereas people with negative

\footnotetext{
${ }^{1}$ Empirically, Hong, Lim, and Stein (2000) show that, controlling for firm size, momentum profits are decreasing in analyst coverage, thus supporting the notion that momentum is caused by slow information diffusion as suggested by the model of Hong and Stein (1999). Chordia and Shivakumar (2002) find that momentum profits are largely predictable from a set of macroeconomic variables, proposing a rational explanation for momentum. Cooper, Gutierrez, and Hameed (2004) find that momentum returns are entirely captured by lagged market returns, and suggest a behavioral explanation of momentum. For further discussions on the causes of momentum, see Conrad and Kaul (1998), Moskowitz and Grinblatt (1999), Grundy and Martin (2001), and Grinblatt and Han (2005).
} 
sentiment make pessimistic ones [Bower (1981, 1991); Arkes, Herren, and Isen (1988); Wright and Bower (1992); among others].

We augment the Hong and Stein (1999) arguments to establish a link between sentiment and momentum. Their framework indicates that news diffuses slowly through the actions of different sets of "newswatchers" that sequentially react to news, and this creates momentum. A class of "momentum traders" trades reflexively in response to past price movements. Some momentum traders mistake price movements due to previous momentum trades as fundamental news movements. Their reactive trades set off an overreaction that eventually is corrected as momentum positions are reversed. We hypothesize that "newswatchers" will underreact more strongly when they receive information that contradicts their sentiment due to cognitive dissonance [Festinger (1957)]. This implies that bad (good) news among loser (winner) stocks will diffuse slowly when sentiment is optimistic (pessimistic). In turn, this will lead to momentum, albeit driven by the loser portfolio in optimistic sentiment periods and the winner portfolio in pessimistic sentiment periods. Although this argument alone predicts symmetric momentum across sentiment periods, as a practical matter momentum may be more pronounced when sentiment is optimistic because arbitraging cognitive dissonance in these states requires the costly short selling of loser stocks.

To ensure that our sentiment measure is free of macroeconomic influences, like Baker and Wurgler $(2006,2007)$, we conduct our investigation using the residual from the regression of the CB Index on a set of macroeconomic variables. The variables include growth in industrial production, real growth in durable, non-durable, and services consumption, growth in employment and a National Bureau of Economic Research (NBER) recession indicator. ${ }^{2}$ Furthermore, in our robustness checks, we also consider the alternative index for investor sentiment constructed by Baker and Wurgler $(2006,2007)$.

To summarize our results, we find that when sentiment is optimistic the six-month momentum strategy yields significant profits, equal to an average monthly return of $2.00 \%$. However, when investor sentiment is pessimistic, momentum profits decrease dramatically to an

\footnotetext{
${ }^{2}$ These indicators are used in Baker and Wurgler $(2006,2007)$ to extract "excessive" investor sentiment from the
} sentiment index developed in Baker and Wurgler (2006). 
insignificant monthly average of $0.34 \%$. Further, we find that momentum within periods of optimism arises primarily from continuing underperformance of losers during these periods.

Our basic result of strong momentum in optimistic periods and virtually no momentum in pessimistic periods survives a host of robustness checks, including controls for market returns and firm size. We orthogonalize analyst coverage to market capitalization [along the lines of Hong, Lim, and Stein (2000)] and find that our result obtains across terciles sorted by residual analyst coverage. As controls for risk, we use a standard CAPM, a Fama and French (1993) approach, and a conditional version of the CAPM, where the betas are allowed to vary with sentiment, and find that our result survives all three methods.

To shed further light on the source of our results, we use intra-day transactions data to estimate stock-by-stock order imbalances across optimistic and pessimistic periods, separately for large and small trades. Our analysis indicates that small investors are slow to sell losers during optimistic periods. This finding supports the argument that bad news causes cognitive dissonance amongst the smaller, naïve investors when they have optimistic beliefs. On the other hand we find that large (and presumably more sophisticated) investors are net sellers of losing stocks in the formation periods of momentum portfolios, suggesting that they respond more promptly to negative information. Further analysis based on the responses of small and large investors to earnings surprises lends additional support to these conclusions.

We also find that investor sentiment provides an important link between short-run continuation and the long-run stock price reversal as predicted by the Hong and Stein (1999) model. Specifically, we examine the long-run behavior of optimistic and pessimistic momentum portfolios five years after portfolio formation and find that momentum profits reverse significantly after optimistic periods, with an average monthly return of $-0.49 \%$, whereas momentum profits after pessimistic periods do not.

In a related and significant paper, Cooper, Gutierrez, and Hameed (2004) suggest that investor biases will be more accentuated after market gains, and show that momentum is profitable only after market increases. Our study partitions momentum profits on our sentiment 
measure, which is an exogenous proxy of agents' propensity to form erroneous beliefs. While we confirm the results of Cooper, Gutierrez and Hameed (2004), we show that sentiment has incremental power to explain momentum-induced profits even after accounting for market returns. Chordia and Shivakumar (2002) show that momentum profits are only significant in periods in which the economy is expanding and attribute their finding to cyclical variation in expected returns. These authors are careful, however, to point out that their finding does not rule out a sentiment-based explanation, ${ }^{3}$ and by examining the relation between our (orthogonalized) sentiment measure and momentum, such a rationale is what we pursue.

Other recent literature has produced important evidence that suggests that sentiment affects stock prices. ${ }^{4}$ This has led several authors to explore the relationship between investor sentiment and various stock market anomalies. Thus, investor sentiment has been linked to the post earnings announcement drift [Livnat and Petrovic (2008)], fund flows and the value effect [Frazzini and Lamont (2008)], corporate disclosure [Bergman and Roychowdhury (2008)], IPOs [Cornelli, Goldreich, and Ljungqvist (2006)], and the size effect [Baker and Wurgler (2006, 2007)]. Our study fits into this literature by analyzing the relationship between investor sentiment and momentum, an important stock market anomaly.

The remainder of this paper is organized as follows. Section 1 describes the data and the empirical methodology. Section 2 presents the results, along with a discussion of the sensitivity analysis, robustness checks and further examinations. Section 3 concludes the paper.

\section{Data and Methodology}

We use all common stocks (share codes 10 and 11) listed in the New York and American Stock

\footnotetext{
${ }^{3}$ Chordia and Shivakumar (2002) suggest that the challenge to this rationale would be to provide an explanation of why investors misinterpret macro information but not firm-specific information. Our sentiment-based argument provides such an explanation, since our notion is that optimism about the overall economy can alter the investment choice regarding individual companies.

${ }^{4}$ See, for example, Hirshleifer and Shumway (2003), who use sunshine to capture investors' mood, and confirm that returns are higher on sunnier days. Edmans, Garcia, and Norli (2007) capture mood by using sporting events, and find that after losses in international competitions, stock markets of losing nations fall. Charoenrook (2003), Brown and Cliff (2005) and Lemmon and Portniaquina (2006) use consumer confidence indices constructed from household surveys to proxy investors' sentiment, and find that asset returns decline following periods of optimism. Baker and Wurgler (2006) create a sentiment index from market-based variables and arrive at similar conclusions.
} 
Exchanges (NYSE and AMEX respectively) from the Center for Research in Security Prices (CRSP) monthly file. The sample time period is from February 1967 to December 2008, for which the CB Index is available.

We construct momentum portfolios using the methodology of Jegadeesh and Titman (1993). In each month $t$, we sort all stocks in decreasing order of their returns for the past $J$ months. Based on these rankings, ten equally weighted portfolios are formed. The top decile is termed the "winners" portfolio, and the bottom decile the "losers" portfolio. Every month, the strategy takes a long position in the winner portfolio and a short position in the loser portfolio, held for $K$ months. We construct overlapping portfolios to increase the power of our tests. Specifically, we close the position initiated in month $t-K$ in both the winner and loser portfolios and take a new position using the winners and losers of month $t$. Therefore, in each month, we revise $1 / K$ of the stocks in the winner and loser portfolios, and carry over the rest from the previous month. ${ }^{5}$ In order to avoid microstructure biases, we allow one month between the end of the formation period and the beginning of the holding period, and delete all stocks that are priced less than one dollar at the beginning of the holding period.

As mentioned earlier, for the main part of our analysis we measure investor sentiment using the monthly time series of consumer confidence sentiment constructed by the CB. This survey begins on a bimonthly basis in 1967 and converts to a monthly series in $1977 .{ }^{6}$ The CB questionnaire is sent to 5,000 randomly selected households in the United States, and asks participants five questions about their outlook for the economy. ${ }^{7}$ The scores for each question are calculated as the number of favorable replies, divided by the sum of favorable and unfavorable replies. The scores on the five questions are amalgamated to form the overall Consumer Confidence Index. In previous research, the index has been used to predict household

\footnotetext{
${ }^{5}$ For example, for the six-month formation-holding period strategy $(J, K=6)$, in each month $t+1$, the winner portfolio is comprised of $1 / 6$ (winners from $t-1$ ) $+1 / 6$ (winners from $t-2$ ) $+\ldots+1 / 6$ (winners from $t-6$ ), and correspondingly for the loser portfolio. Note that month $t$ is skipped.

${ }^{6}$ For the period that the index is available on a bimonthly basis, we follow Qiu and Welch (2006) in using linear interpolation to obtain monthly observations.

${ }^{7}$ The questions are the following: 1) How would you rate present general business conditions in your area? 2) What would you say about available jobs in your area right now? 3) Six months from now, do you think that the business conditions in your area will be better, same or worse? 4) Six months from now, do you think there will be more, same, or fewer jobs available in your area? 5) Would you guess your total family income to be higher, same, or lower 6 months from now?
} 
spending activity [Acemoglu and Scott (1994); Ludvigson (2004)], as well as a proxy for investor sentiment [e.g., Lemmon and Portniaguina (2006); Fisher and Statman (2002)].

In order to purge the effects of macroeconomic conditions from the CB Index, we regress this monthly index on six macroeconomic indicators: growth in industrial production, real growth in durable consumption, non-durable consumption, services consumption, growth in employment, and an NBER recession indicator. We use the residuals from this regression as the sentiment proxy. ${ }^{8}$

To identify whether a particular formation period is optimistic or pessimistic, we calculate a weighted rolling average of the sentiment level for the three months prior to the end of the formation period. We give a weight of three to sentiment in the prior month, two to the one in the month prior to that and one to the month three months prior to the current month. ${ }^{9,10} \mathrm{~A}$ formation period is classified as optimistic (pessimistic) if the three-month rolling average ending in month $t$ belongs in the top (bottom) $30 \%$ of the three-month rolling average sentiment time series. In order to ensure that our analysis is not sensitive to the definition of sentiment states, we also consider $20 \%$ and $40 \%$ cut-off points, and as reported later, the results are substantively similar.

Because we form overlapping portfolios, in each holding period month we hold stocks from different formation periods, across which sentiment can differ. In order to calculate the average sentiment in these formation periods, we first calculate whether each of these formation periods is optimistic or pessimistic as explained above, and then tally how many were optimistic or pessimistic. If all the formation periods are classified as optimistic (pessimistic) the particular holding period month is classified as optimistic (pessimistic), with the rest being the "mild"

\footnotetext{
${ }^{8}$ This sentiment indicator is also used by McLean and Zhao (2009).

${ }^{9}$ We classify the momentum portfolio, formed at the end of month $t$, as optimistic or pessimistic using the weighted average of the residual sentiment from the three previous months as follows: $3 / 6$ *residual $(\mathrm{t})+2 / 6 *$ residual $(t-1)$ $+1 / 6 *$ residual(t-2). This weighting scheme is chosen in order to assign more weight on the most recent sentiment observation when we predict momentum profits, and is similar to the one used in Lakonishok, Shleifer and Vishny (1994, p. 1550). However, our main results remain unchanged even when we use a simple arithmetic average.

${ }^{10}$ Since sentiment is announced with a one-month delay, the use of residuals from month $t, t-1$ and $t-2$ to calculate the rolling sentiment measure actually corresponds to sentiment during months $t-1, t-2$, and $t-3$. We also consider alternative sentiment specifications based on two and four month lags and find that our results continue to hold. These results are reported later in the paper.
} 
sentiment months. ${ }^{11}$

To test whether momentum profits in each sentiment state are equal to zero, we regress the time series of average monthly momentum profits on three dummy variables for OPTIMISTIC, MILD, and PESSIMISTIC sentiment, with no intercept. To test if mean profits in optimistic sentiment periods are different from profits in pessimistic sentiment periods, we regress average monthly momentum profits on MILD and OPTIMISTIC sentiment dummies, with a constant. This approach, which is similar to that of Cooper et al (2004), helps preserve the full-time series of returns, and allows us to estimate $t$-statistics that are robust to autocorrelation and heteroskedasticity using Newey and West (1987) standard errors.

Later in the paper, we also calculate the long-run performance of the momentum portfolios, focusing on the six-month formation/holding period strategy. For that analysis, we follow the methodology employed by Jegadeesh and Titman (2001), whereby for each momentum portfolio constructed, we define an event date that is 13 months following the initial formation date. ${ }^{12}$ After this date, we hold the portfolio for five years, and test whether portfolios formed in optimistic formation periods behave differently from those formed after pessimistic periods.

Table 1 presents descriptive statistics for our sentiment index. Panel A is based on the raw data of consumer confidence provided by the CB. Panel B reports the three-month rolling average using the residuals from regressing the raw $\mathrm{CB}$ data on a set of macroeconomic variables. The raw CB Index, as shown in Figure 1, rises during the late 1960s, mid 1980s, and late 1990s, and falls during the 1970s and early 1990s. These patterns are in line with the evidence for investor sentiment discussed by Baker and Wurgler (2006). The fall in sentiment for the period 2006-2008 seems to be an early sign of the recent recession. As shown in Figure 1, the 3-month rolling weighted average of this residual, which is the sentiment measure used in

\footnotetext{
${ }^{11}$ For example, assuming $\mathrm{J}=K=6$, in June 1980 we hold stocks selected from six ranking periods ending in May, April, March, February, and January. For each of the six ranking periods, we calculate the sentiment level in the previous three months, and classify each formation period as being high, mild, or low sentiment.

${ }^{12}$ Thus, for instance, the portfolio held in June 1980, is initiated in November 1979 (skipping December). This portfolio is based on overlapping returns, thus it is an equally-weighted portfolio of the positions initiated in January, February, March, April, and June. For this portfolio, the post-holding period starts in January 1981, after which we continue to hold the same portfolio using the equally-weighted structure for a period of five years.
} 
our main analysis, tracks the raw $\mathrm{CB}$ index closely (i.e., shows an upward trend when the index is rising and vice versa). ${ }^{13}$

A robust finding in the literature is that investor sentiment is reflected in the size premium [Lee, Shleifer, and Thaler (1991); Baker and Wurgler (2006, 2007); Lemmon and Portniaguina (2006)]. The usual interpretation of this finding is that optimistic investors are drawn to small stocks, thereby reducing the size premium in the following period. In order to validate our sentiment proxy, we regress the three-month average residual sentiment ending in month $t$ on the Fama and French (1993) SMB portfolio return in month $t+1 .{ }^{14}$ We obtain a coefficient of $-0.023(t$-value $=-3.16)$ on SMB, which corroborates our sentiment proxy.

\section{The Hypothesis and Empirical Evidence on Momentum Profits across Sentiment States}

Our central hypothesis is that sentiment may influence momentum by way of cognitive dissonance. The argument builds upon Hong and Stein (1999), who indicate that momentum arises due to slow diffusion of news. We propose that negative (positive) information about stocks when sentiment is optimistic (pessimistic) will conflict with investors' prior beliefs, and thus cause cognitive dissonance. As a result, information opposed to the direction of sentiment will diffuse particularly slowly and cause momentum.

Although the preceding argument alone implies a symmetric momentum effect in optimistic and pessimistic sentiment periods, previous research suggests that it may be more pronounced in optimistic sentiment periods. Specifically, because of limits to arbitrage, it would be more difficult for arbitrageurs to exploit cognitive dissonance in optimistic periods, as this entails costly short selling in loser stocks [D'Avolio (2002)]; whereas arbitraging cognitive dissonance in pessimistic states only requires buying winners. This observation suggests that momentum may not be symmetric across optimistic and pessimistic sentiment states.

\footnotetext{
${ }^{13}$ The fact that the orthogonalization does not materially affect the behaviour of the index is in line with the findings of Baker and Wurgler (2006).

${ }^{14}$ We thank Ken French for making the SMB data available on his website (http://mba.tuck.dartmouth.edu/pages/faculty/ken.french/).
} 


\subsection{Investor Sentiment and Short-Run Momentum Profits}

Our first empirical test examines the profitability of the momentum strategy conditioning on pessimistic and optimistic investor sentiment states. Table 2 presents the results for strategies that are based on a six-month ranking period $(J)$ and holding periods $(K)$ of three, six, and twelve months sorted by investor sentiment. In Panel A (B) pessimistic sentiment is defined as the bottom $30 \%(40 \%)$ of the rolling average sentiment time series. ${ }^{15}$

Table 2 demonstrates that momentum profits are sensitive to our sentiment measure. Thus, in Panel A, for the $J=K=6$ strategy, average monthly profits in optimistic periods are highly significant at $2.00 \%$; they decrease to $1.46 \%$ per month in mild sentiment months, and shrink to a statistically insignificant $0.34 \%$ in months with pessimistic sentiment. ${ }^{16}$ When the holding period is extended to twelve months $(J=6, K=12)$, average monthly profits in optimistic (mild) periods are $1.27 \%(0.85 \%)$, while they decline to $0.09 \%$ in pessimistic periods. Similarly, when the holding period is condensed to three months $(J=6, K=3)$, average monthly profits in optimistic (mild) periods are $2.27 \%$ (1.44\%), declining to an insignificant $0.29 \%$ in pessimistic periods. Comparable results are shown in Panel B, confirming that the choice of cut-off point for optimistic and pessimistic sentiment does not materially affect our conclusions.

We also observe from Table 2 that the higher momentum profits in optimistic periods arise primarily because loser stocks continue to underperform in subsequent periods. This indicates that bad news diffuses slowly when investors are optimistic, because cognitive dissonance causes investors to disregard negative information about loser stocks. ${ }^{17}$ In

\footnotetext{
${ }^{15}$ Using a $20 \%$ cutoff for optimistic/pessimistic sentiment yields similar results that are not reported for brevity, but are available from the authors upon request.

${ }^{16}$ The unconditional momentum strategy for the period 1966-2008, based on $J, K=6$, yields an average monthly profit of $1.38 \%$ (an unreported result). This figure is comparable with studies of momentum for analogous time periods [Lee and Swaminathan (2000); Jegadeesh and Titman (2001)].

${ }^{17}$ The arguments of Veronesi (1999) suggest that uncertainty in the loser and winner portfolios may depend on sentiment, as sentiment provides an indication of investors' perceptions of the general state of the economy. To examine the relationship between uncertainty and sentiment we compute average return volatility of loser and winner stocks for the 12 month period centred on portfolio formation date conditional on sentiment. We find that in optimistic periods, return volatility in the two portfolios is similar $(17 \%$ for the loser stocks and $16.5 \%$ for winner stocks). We also find that the volatility of losers (winners) is slightly lower (higher) in pessimistic periods, equal to $15.4 \%(16.9 \%)$. These results suggest that while sentiment affects uncertainty in the momentum portfolios, it has a very modest economic impact.
} 
pessimistic periods, momentum does not obtain because both winner and loser stocks earn positive holding-period returns of roughly the same order of magnitude, thus negating the return spread between winning and losing deciles. This is consistent with the notion that the arbitraging of cognitive dissonance in pessimistic states (which requires buying winners) is effective in enforcing market efficiency across winners and losers in pessimistic states. ${ }^{18}$ [We will shed more light on this issue in Section 2.3.] An interesting aside, which is not the focus of our paper, but deserves attention in future research, is that the post-formation period returns of all deciles are higher after pessimistic formation periods than after optimistic ones. ${ }^{19}$

The finding that momentum profits are significant in "mild" sentiment months is in line with extant experimental literature in decision making, which consistently documents that on average subjective beliefs are more optimistic than objective probabilities [e.g., Weinstein (1980), Slovic (2000), Puri and Robinson (2007)]. ${ }^{20}$ Our evidence lends support to these studies as we show that "mild" sentiment states entail some excessive optimism, giving rise to significant momentum profits, which increase (decrease) substantially when sentiment becomes more optimistic (pessimistic).

As stated earlier, these results corroborate the analysis of Chordia and Shivakumar (2002) and Cooper, Gutierrez, and Hameed (2004), who respectively find that momentum profits vary significantly according to whether the market has been rising or falling or whether the economy has been expanding or contracting. Going further, however, our analysis explicitly links the time series of momentum profits to sentiment. Our analysis accords with the general notion that the

\footnotetext{
${ }^{18}$ If managers themselves disclose good news promptly to boost their stock prices in pessimistic periods, as shown by Bergman and Roychowdhury (2008), then good news will be propagated quickly, counteracting the cognitive dissonance of investors toward good news in times of pessimism. This phenomenon may also reduce the performance of winners in the holding period, thus contributing to decreased momentum.

${ }^{19}$ The finding is consistent with the notion that in periods of pessimism, investors are less inclined to take on risk, and thus set stock prices lower in pessimistic formation periods, so that future returns are high following these periods [Baker and Wurgler (2006)]. In additional analysis we calculate the average $\mathrm{P} / \mathrm{E}$ ratios of each portfolio at the end of the formation period and find that they are lower (and statistically different) in pessimistic periods than in optimistic ones (unreported result). This finding also suggests that stocks generally become undervalued in pessimistic formation periods. The positive returns in the three- to twelve-month holding periods following pessimistic formations are consistent with Veldekamp (2005), who argues that the paucity of information in times of pessimism (because of low investment activity) causes a "slow boom" (gradual rise in stock prices) during the ensuing periods.

${ }^{20}$ Various studies examine the microeconomic foundations of average optimism in beliefs. Brunnermeier and Parker (2005) suggest that it is a consequence of anticipatory utility and Bracha and Brown (2010) that it is a consequence of affective decision making.
} 
profitability of the momentum trading style is susceptible to significant time variation, since the returns of the winner and the loser portfolios do not preserve their spread across optimistic and pessimistic sentiment states.

\subsection{Is the Effect of Investor Sentiment on Momentum Profits Robust?}

This section examines the robustness of the evidence that momentum profits are only significant during periods of optimistic sentiment. Unless stated otherwise, in this section we analyze the six-month formation and holding period strategy $(J=6, K=6)$, and define sentiment as in Panel A of Table $2 .^{21}$

\subsubsection{Investor Sentiment, Momentum, and Market States}

Cooper, Gutierrez, and Hameed (2004) test whether the momentum profits are related to past market returns. They identify UP and DOWN market states using the returns of the market for a 36-month period prior to the beginning of the strategy's holding period. If this return is positive (negative), they classify the market state as UP (DOWN). Then they compute momentum profits after UP and DOWN markets. Their results indicate that momentum profits are significant only after UP markets. This leads the authors to conclude that positive market returns amplify biases, which ultimately lead to momentum.

Market returns can, of course, be related to investor sentiment [Otoo (1999)], because, for example, as market returns increase, investors may potentially become more optimistic. However, the relationship may not be exact for two reasons. First, some investors could hold contrarian expectations. ${ }^{22}$ These investors may become pessimistic when they perceive that the market has climbed too high. Second, our measure of sentiment is a broad survey on aspects other than financial markets, and is likely to be affected by factors over and beyond market returns. Indeed, for our entire sample period, we find that the correlation of the time series of lagged 36-month market returns and the average residual sentiment for the past three months is

\footnotetext{
${ }^{21}$ Defining sentiment as in Panel B of Table 2 yields very similar results, which are available upon request.

${ }^{22}$ See Grinblatt and Keloharju (2000), Chordia, Roll, and Subrahmanyam (2002), and Goetzmann and Massa (2002) for evidence on contrarian investors.
} 
0.24. This confirms that the relationship between market returns and investor sentiment is less than perfect.

Nevertheless, a correlation of 0.24 is significant and merits investigation. Therefore, we also classify each formation period into UP or DOWN market states independently of investor sentiment as in Cooper, Gutierrez, and Hameed (2004). We calculate the return of the CRSP value-weighted index, in Table 3, including dividends for the 36-month (Panels A1 and B1), 24month (Panels A2 and B2) and 12-month (Panels A3 and C3) period prior to the beginning of the strategy's holding period. If this return is positive (negative), we classify the market state as UP (DOWN). We then derive momentum profits for optimistic and pessimistic periods during UP (Panel A) and DOWN (Panel B) markets.

These results are reported in Table 3. From Panels A1 and B1 it can be seen that out of the 500 holding period months in the sample, $436(87.2 \%)$ occur in UP markets and only 64 $(12.8 \%)$ in DOWN markets. Interestingly, in UP market states, we find considerable variation in investor sentiment, as 69 periods (or 16\%) are classified as pessimistic, 254 (or 58\%) as mild and 113 (or 26\%) as optimistic. This provides support to the notion that market run-ups do not completely overlap with investor optimism.

Momentum strategies in DOWN markets, as shown in Panel B of Table 3, generally produce insignificant momentum profits, regardless of investor sentiment. However, the number of observations in each sentiment group is very small and, therefore, these results do not allow meaningful interpretation. Momentum profits in UP markets, as Panel A of Table 3 shows, vary with investor sentiment. Specifically, in Panel A1 (36-month market return), momentum profits in optimistic periods are highly significant at a monthly average of $2.12 \%$. This average decreases to $1.55 \%$ in mild sentiment months, and to an insignificant $0.87(t$-value $=1.51)$ in pessimistic months. Similar, but stronger, results are reported in Panels A2 (24-month market return) and A3 (12-month market return). These results are consistent with our previous findings, which show that momentum profits are significantly larger when investor sentiment is optimistic. 
In Table 4 we report regression results based on the regression model of Cooper, Gutierrez, and Hameed (2004) (Table V, p. 1361), augmented with investor sentiment. Specifically, we estimate the following model (omitting time subscripts):

$$
\text { Profits }=b_{0}+b_{1} \text { Sentiment }+b_{2} \text { Market }+b_{3} \text { Market }^{2}+u
$$

The variable Profits is the time series of average monthly momentum profits in month $t$. In the regression, Sentiment is defined as the 3-month weighted rolling average of the sentiment residual ending in month $t-1$. Market is the lagged market return of the value weighted index including dividends during the 12 (Panel 1), 24 (Panel 2), and 36 (Panel 3)- month periods prior to the beginning of the strategy's holding period. Market $^{2}$ is the square of the market return.

Panel A reports the results from the regression of Cooper et al (2004) augmented with sentiment and shows that momentum profits increase with the market return, but decrease with the squared market term, indicating a nonlinear relationship, and confirming the results of Cooper, Gutierrez, and Hameed (2004). ${ }^{23}$ The results also show that the coefficient of Sentiment is positive and significant across all market return specifications (12, 24 and 36-months). Specifically, in Panel A1, when we use a 12-month lagged market return, the coefficient on Sentiment is equal to 0.327 with a $t$-value of 3.33 . When we use the 24-month lagged market return (Panel A2) the coefficient is 0.309 with a $t$-value of 3.37, and when we use the 36-month lagged market return (Panel A3) it is equal to 0.272 with a $t$-value of 2.95. In addition, the results show that the effect of Market on momentum decreases when market returns are calculated over shorter time periods. For the 36-month period the coefficient on Market is 0.109 with t-value 3.53 and decreases to a mildly significant 0.061 with a $t$-value 1.69 for the 12 -month period. Interestingly, while these results display that Sentiment predicts momentum profits independently of market returns they also show that it is a stronger predictor when the market return is calculated over shorter periods.

In Panel B we run the regression without the squared market term to compare the economic impacts of Market and Sentiment on momentum profits. Using the sample standard

\footnotetext{
${ }^{23}$ In unreported analysis (available on request) we run a regression identical to that of Cooper, Gutierrez, and Hameed (2004) (without the sentiment variable) and find results similar to theirs.
} 
deviations of the two variables and the regression coefficients we find that, when the 36-month market return is used, a one standard deviation increase in Sentiment implies an increase in average monthly momentum profits of $0.54 \%$, whereas an analogous move in Market has an impact on momentum profits of $0.47 \%$. For the regression involving the 24-month Market (Panel B2), the corresponding magnitudes are $0.60 \%$ and $0.50 \%$, and for the 12-month Market (Panel $\mathrm{B} 1)$, they are $0.67 \%$ and $0.51 \%$, respectively.

In Panel $\mathrm{C}$ we completely de-link our sentiment measure from market effects by using a sentiment measure that is orthogonal to market returns and macroeconomic variables. To obtain this measure we regress raw sentiment on market returns (12-month market returns in Panel C1, 24-month in Panel C2 and 36-month in Panel C3) and macroeconomic variables and use the residuals from this regression to calculate Sentiment. ${ }^{24}$ The results show that Sentiment is positive and significant in all three specifications of the market return, and highlight that sentiment has a distinct impact on momentum profits beyond market returns. ${ }^{25}$

Overall, while we confirm the results of Cooper, Gutierrez, and Hameed (2004), the results in Tables 3 and 4 show that the investor sentiment effect on momentum profits goes beyond the market-state effect documented by these authors. Thus, our findings indicate that investor sentiment captures significant variation in momentum profits even after controlling for the state of the capital market.

\subsubsection{Is it an Analyst Coverage or a Size Effect?}

A large literature suggests that return predictability is stronger for smaller companies, which are held mostly by individual investors [Nagel (2005)], and entail higher arbitrage costs [D'Avolio (2002), Jegadeesh and Titman (1993, 2001)]. Further, Hong, Lim, and Stein (2000) show that momentum is stronger for stocks with low analyst coverage, because lower analyst following slows the diffusion of news. In this section, we explore whether our previous results, reported in

\footnotetext{
${ }^{24}$ The correlations between Sentiment and Market in this regression are small (less than 0.07 in absolute terms) in all three panels, illustrating that the process of calculating the 3-month rolling weighted average does not induce correlation between the variables.

${ }^{25}$ A version of the regression in Panel C for only UP market states yields substantively similar results.
} 
Table 2, depend on the size or analyst coverage of the company.

Table 5 presents results for the sample stratified by analyst following. We use the number of IBES analysts making one-year-ahead EPS forecasts as a proxy for analyst coverage, and term this variable analysts. We then match analysts in month $t$ with the CRSP market capitalization (size) at the end of the month $t$-1. As in Hong, Lim, and Stein (2000), in order to isolate the role of analyst following vis-à-vis size, we perform the monthly cross-sectional regression $\log (1+$ analysts $)=a+b^{*} \log ($ size $)+e$. Then, in each month, we form three equal-sized samples in increasing order of the residuals $(e) .{ }^{26}$ Panels $\mathrm{A}, \mathrm{B}$, and $\mathrm{C}$ document the momentum profits for the low, mid, and high residual coverage stocks, respectively.

As can be seen from this table, the difference in momentum profits between optimistic and pessimistic periods is very similar across the three groups, and momentum profits during pessimistic periods are insignificant throughout. Note that returns of extreme losers are lower (more negative) for low coverage stocks during non-pessimistic periods. While we have verified that these differences are not statistically significant, the point estimates are consistent with the Hong, Lim, and Stein (2000) notion that low coverage slows the diffusion of news, causing stronger momentum. Overall, the sentiment effect documented in Table 2 is robust to analyst coverage, as the effect of sentiment on momentum profits is preserved across all the coverage groups.

Next, we use the size breakpoints on Ken French's website to construct deciles by market capitalization. We then apply our momentum strategy separately to companies in the five smaller-firm groups and the other five groups. These results are reported in Table 6 and show that sentiment affects momentum for both small and large stocks. For small stocks (Panel A), we observe that momentum profits in optimistic periods decline from $2.14 \%$ to $1.72 \%$ in mild sentiment periods and to an insignificant $0.46 \%$ in pessimistic periods. The corresponding figures for large companies are $0.86 \%, 0.81 \%$, and $0.26 \%$.

Our evidence that momentum is generally larger for smaller companies confirms the

\footnotetext{
${ }^{26}$ Following Hong, Lim and Stein (2000), analyst coverage is matched to firms in the momentum portfolios six months prior to the beginning of the formation period.
} 
findings of Jegadeesh and Titman (1993, 2001). Further, the evidence that the effect of sentiment is much more dramatic in smaller companies (an average monthly return differential in the amount of $1.68 \%$ vis-à-vis $0.60 \%$ for large companies) supports the argument of Baker and Wurgler (2006) that the influence of sentiment tends to be more pronounced in the smaller companies that are harder to value and hence more prone to subjective evaluations. This finding is also consistent with Hong and Stein (1999), who argue that news about small firms diffuses more slowly, because investors face larger fixed costs of information acquisition in these firms, and thus uncover relevant news less speedily than in large firms.

\subsubsection{Is it Risk?}

While the evidence so far suggests that conditioning on investor sentiment has a dramatic impact on the profits of momentum strategies, we have not addressed the possibility that the higher (lower) returns of the winner (loser) portfolio during periods of optimism load more (less) strongly on economic risk factors. We now tackle this issue by estimating CAPM, Fama and French (FF), and conditional CAPM (CCAPM)-adjusted momentum returns across different sentiment states.

In accordance with Cooper, Gutierrez, and Hameed (2004), we perform the risk adjustment by forming a time series of raw momentum returns corresponding to each event month of the holding period. Specifically, to form CAPM- and FF-risk adjusted profits, for each holding period month, portfolio returns are regressed on the appropriate factors and a constant. In this manner, we obtain estimated factor loadings for each portfolio and holding period month, which we use to derive risk-adjusted profits as follows:

$$
r_{k t}^{a d j}=r_{k t}-\sum_{t} \beta_{i k} f_{i t},
$$

where $r_{k t}$ represents the raw returns of each momentum portfolio for the strategy in the holding period month $K$, in calendar month $t, f_{i t}$ is the realization of factor $i$ in calendar month $t$, and $\beta_{i k}$ is the estimated factor loading in month $K$ on $f_{i t}$. We use the excess return of the value-weighted market index, $R_{m}$, over the one-month Treasury-bill return, $R_{f}$ as the market portfolio in the CAPM, and, additionally, the return differential between small and big companies (SMB), and high and low book-to-market companies (HML), for the FF risk adjustment. 
The above models rely on the assumption that the covariance of momentum portfolio returns with the risk factors is constant. If this is not the case, as discussed in Grundy and Martin (2001), a more appropriate test would be to condition betas on sentiment in order to control for the possibility that the patterns we document reflect sentiment-related time-varying systematic risk. To do this we use a CCAPM-based robustness check, where we allow the covariance between the returns of momentum portfolios with the excess market return to vary with investor sentiment. Specifically, we estimate risk-adjusted returns using the following model:

$$
r_{k t}^{a d j}=r_{k t}-\left(\beta_{i k}-\beta_{i k}^{\text {sent }} * \text { Sentiment }_{t-j}\right)\left(R_{m}-R_{f}\right),
$$

where $r_{k t}$ represents the raw returns of each momentum portfolio for the strategy in the holding period month $K$ in calendar month $t, \beta_{i k}$ is the estimated factor loading in month $K$ on the excess market return and $\beta_{i k}^{\text {sent }}$ is the factor loading in month $K$ on the interaction between the excess market return and investor sentiment during the formation period. ${ }^{27}$ The time-varying betas argument predicts that the covariance between momentum profits and excess market returns increases when sentiment is optimistic; therefore returns increase accordingly to compensate for the increased co-variation.

Table 7 shows the CAPM, FF and CCAPM-adjusted momentum profits. The pattern of momentum profits in Table 2 remains robust to these risk adjustments. Momentum profits are highly significant, at monthly averages of $2.03 \%$ (CAPM), $2.08 \%$ (FF), and $2.03 \%$ (CCAPM) when the strategy is implemented in optimistic investor sentiment periods. However, in pessimistic periods momentum profits drop remarkably to a monthly average return of $0.48 \%$ (CAPM), $0.96 \%$ (FF), and $0.47 \%$ (CCAPM). Note that the CAPM and the CCAPM-adjusted returns are virtually indistinguishable, suggesting that beta is not materially related to investor sentiment. This result is in line with the analysis of Baker and Wurgler (2006).

Overall, while we cannot rule out every possible risk-based explanation of our findings, it is reasonable to conclude that the performance of momentum strategy in periods of optimistic

\footnotetext{
${ }^{27}$ Because we perform overlapping strategies for each portfolio return observation we have CB residuals from $K$ formation periods. In Equation (3), Sentiment is the average sentiment from these $K$ formation periods.
} 
investor sentiment is not explicable by rational risk premia as modelled in standard settings, namely, the CAPM, the conditional CAPM, and the Fama and French (1993) framework.

\subsubsection{Is the CB Sentiment Index Forecasting Future Macroeconomic Conditions?}

Although traditional risk-based models do not appear to account for the sentiment effect on momentum profits, this effect may still be related to some form of rational pricing if our sentiment measure reflects future macroeconomic activity, which determines holding period returns. In this section we construct our sentiment measure by controlling for proxies for future macroeconomic conditions. Specifically, we replicate the analysis in Panel A of Table 2 by orthogonalizing the CB index to current macroeconomic indicators (described in Section 1), their one-quarter ahead values, ${ }^{28}$ and the closing value of VIX at the end of the month in which sentiment is measured. ${ }^{29}$ The inclusion of the one-quarter ahead macroeconomic variables allows us to control for future macroeconomic conditions. We include VIX as a proxy for macroeconomic expectations since it is obtained primarily as a consequence of trading by sophisticated options investors [Lakonishok, Pearson and Poteshman (2007)]. ${ }^{30}$ All of the other calculations remain unaltered, with the difference that the sample period of this test is shorter as VIX is available from January $1985 .^{31}$

Table 8 reports results for $J=K=6$. [Results for other $J, K$ combinations considered in Table 2 are not reported for brevity but are qualitatively similar.] As can be seen, the results remain essentially unchanged even when we orthogonalize the $\mathrm{CB}$ index with respect to future macroeconomic conditions and VIX. For example, momentum profits in optimistic sentiment states are highly significant at a monthly average of $2.42 \%$. They decline to $1.51 \%$ in mild sentiment periods and to an insignificant $0.27 \%$ in pessimistic periods. These findings suggest

\footnotetext{
${ }^{28}$ The current value of the NBER recession dummy is used.

${ }^{29}$ For a general discussion of VIX (the index options-based volatility index), see Whaley (2009).

${ }^{30}$ The level of the VIX may also be related to sentiment, as shown by Kaplanski and Levy (2010). However, since options are primarily traded by sophisticated investors it is reasonable to assume that the sentiment displayed by the VIX is not as dramatic as that displayed by the CB index. Therefore, we suppose that at least some of the variability in the VIX is related to expectations about future macroeconomic conditions.

${ }^{31}$ The computation of VIX was based on S\&P 100 options till September 19, 2003, and subsequently on S\&P 500 options. Whaley (2009, Footnote 9), suggests a method by which the VIX computation based on S\&P 100 options is adjusted to account for the slightly lower volatility of the S\&P 500 index. The unadjusted and adjusted versions of VIX give identical results; we report results using the unadjusted series.
} 
that our patterns in momentum profits do not arise simply because our sentiment measure forecasts future macroeconomic activity.

\subsubsection{An Alternative Sentiment Index}

In this section, we examine the sensitivity of our results to an alternative index for investor sentiment, which is the measure constructed by Baker and Wurgler $(2006,2007){ }^{32}$ These authors suggest that investor sentiment can be captured by variables that relate to investors' propensity to purchase stock. They construct a time series of sentiment using six proxies: trading volume (measured as total NYSE turnover), ${ }^{33}$ the premium for dividend paying stocks, the closed-end fund discount, the number of IPOs as well as the mean first-day IPO return, and the equity share in new issues. Because these variables are partly related to economic fundamentals, they regress each against growth in industrial production, real growth in durable consumption, non-durable consumption, services consumption, growth in employment, and an NBER recession indicator. Their sentiment index is the first principal component of the residual series from the regressions. For more detail on the construction of the index, see Baker and Wurgler (2006, 2007). Their monthly time series is available from October 1965 to December 2007.

Table 9 reports Table 2-equivalent momentum results for optimistic and pessimistic periods, using the Baker and Wurgler sentiment measure in place of our CB index. All other calculations remain the same as those in Table 2, with the difference that in this table we combine periods of mild and optimistic sentiment. We do this for brevity since these sentiment states yield very similar momentum profits, ${ }^{34}$ and we gain some statistical power by combining the periods; moreover, as discussed in Section 2.1, significant momentum profits in mild sentiment states imply investor optimism in these states as well. The evidence in Table 9 confirms our general relation between momentum profits and sentiment. Specifically, where

\footnotetext{
${ }^{32}$ This index is available from Jeffrey Wurgler's website (http://pages.stern.nyu.edu/ jwurgler/).

${ }^{33}$ To remove the time trend from turnover, Baker and Wurgler $(2006,2007)$ use log turnover minus a five year moving average.

${ }^{34}$ When $J=6, K=3(J=6, K=12)$ the corresponding momentum profits in optimistic periods are $1.71 \%(0.97 \%)$, reducing to an insignificant $0.23 \%(-0.01 \%)$ in pessimistic periods. When momentum profits are partitioned to three sentiment categories, and $J, K=6$, the optimistic and mild sentiment categories yield average momentum profits of $1.40 \%$ and $1.67 \%$, respectively. The corresponding numbers for $K=3$ and $K=12$ are $1.54 \%$ and $1.80 \%$, and $0.70 \%$ and $1.05 \%$.
} 
$J, K=6$, the results show that momentum profits in optimistic and mild periods amount to a monthly average of $1.59 \%$, whereas in pessimistic periods they drop to an insignificant $0.30 \% .{ }^{35}$ Similar results are obtained for the other $J, K$ combinations in Table 2. These findings corroborate our previous results and show that they are not driven by the choice of sentiment index.

\subsubsection{Alternative Lags for Optimistic and Pessimistic Sentiment}

In our analysis so far, we classify each formation period as pessimistic or optimistic using a rolling average of the residual sentiment level during a three-month window just prior to the holding period. In this section, we examine the sensitivity of our results to average sentiment calculated as the average of the two and four months prior to the end of the formation period. ${ }^{36}$

As shown in Panels A (two sentiment lags) and B (four sentiment lags) of Table 10, our main results hold for this alternative sentiment specification. Momentum strategies in optimistic periods consistently yield significant average monthly profits of $1.95 \%$ (Panel A) and $2.10 \%$ (Panel B). These profits, however, decline substantially in pessimistic periods, equaling $0.46 \%$ (Panel A), and $0.62 \%$ (Panel B). The baseline findings are therefore robust to different ways of computing sentiment.

\subsection{Cognitive dissonance and momentum profits}

The evidence in the previous sections shows that momentum is stronger in optimistic sentiment periods, and that this is mainly driven by continued underperformance of the loser portfolio. Our augmented version of the Hong and Stein (1999) theory indicates that this is caused by cognitive dissonance toward negative news during optimistic periods. In this section we conduct a more direct test of this conjecture by examining the market's response to negative earnings surprises for loser stocks, conditional on sentiment. To perform this test, we first identify winners and losers, based on 6-month cumulative returns ending in month $t$, and examine the pricing of earnings surprises in month $t+1$. We use the seasonal random walk model to compute

\footnotetext{
${ }^{35}$ We obtain very similar results when we use $40 \%-40 \%$ or $20 \%-20 \%$ cut-offs for sentiment states.

${ }^{36}$ The calculation of these rolling averages uses equal weights.
} 
standardized unexpected earnings (SUE). In each year-quarter all firms are ranked into deciles according to their SUE, with the top 30\% firms classified as being the "good news" firms, and the bottom $30 \%$ as the "bad news" firms. We calculate cumulative returns in the "impact" (days 1, 1 relative to the earnings announcement) and the "adjustment" period (days 2, 60) to examine whether sentiment affects the speed with which the earnings information is priced. For brevity, we only report results for loser stocks with negative earnings surprises; other results are available upon request.

Table 11 reports the results. Consistent with the predictions of our hypothesis we observe that the post-earnings announcement drift after negative surprises is much stronger when sentiment is optimistic, as the average cumulative return in the adjustment period is $11 \%$ lower. This result, which is in agreement with the findings of Livnat and Petrovits (2008), is consistent with the notion that the market underreacts to adverse information that contradicts the prevailing optimistic sentiment.

In Panel B of Table 11 we examine the effect of this underreaction on momentum profits. We repeat the analysis in Panel A2 of Table 2 by first using all stocks (Panel B1), and then excluding losers with negative earnings surprises (Panel B2) ${ }^{37}$ The results show that, once we exclude losers with negative earnings surprises, average momentum profits in optimistic periods drop remarkably, from $1.92 \%$ to $0.91 \%$ per month. Conversely, when we exclude winners with positive earnings surprises momentum profits in optimistic periods drop to $1.55 \%$ per month (unreported result). This suggests that momentum profits in optimistic sentiment periods are primarily driven by cognitive dissonance toward bad news in the loser portfolio, as predicted by our hypothesis. In mild sentiment periods the contribution of loser stocks with bad news to momentum profits is dampened, which is expected since cognitive dissonance in these periods is weaker.

Overall, the analysis in this section provides further support to our hypothesis, that momentum in optimistic sentiment periods is driven by cognitive dissonance among loser stocks with bad news.

\footnotetext{
${ }^{37}$ In Panel A the figures are slightly different from those in Table 2 because the sample in this table is the intersection of CRSP and COMPUSTAT.
} 


\subsubsection{Cognitive dissonance and investor size}

There is abundance of evidence in the literature that imperfect reactions to new information, like the one we posit due to cognitive dissonance, are more likely to manifest themselves in the trading patterns of smaller, less sophisticated, investors [Odean (1999), Grinblatt and Keloharju (2010)]. Existing evidence also suggests that large institutional investors process a larger information set and make superior trades [Malmendier and Shanthikumar (2007)]. In this section, we analyze small and large investor net order imbalance in the loser portfolio conditional on sentiment, to examine whether cognitive dissonance is primarily a trait of small investors.

We follow Hvidkjaer $(2006,2008)$ in constructing order flow proxies for large and small investors and calculate the averages of these quantities for each momentum portfolio in each month of the formation and holding periods. ${ }^{38}$ Since computing order imbalance requires transactions data, which are not available for the entire sample period, the analysis spans the period 1983 to 2008. Results for optimistic and pessimistic periods appear in Table $13 .{ }^{39}$

As can be seen in Panel A1, small investor order flow for the loser portfolio during optimistic periods is positive and significant in five of six months in the formation period, and turns negative only in the holding period. This supports the argument that unsophisticated investors are slow to sell losers during optimistic periods, prolonging the pricing of bad news. On the contrary, large investors are net sellers of losing stocks in the formation period, suggesting that they respond more promptly to negative information for loser stocks. Large investors also exert some selling pressure on loser stocks in the holding period. It is unlikely, however, that this selling pressure arises from underreaction because large investors sell losers more strongly during the formation period (i.e., for each event month the magnitude of the selling pressure exerted in the formation period is approximately double compared to the holding period). We suggest that this "delayed" selling pressure may reflect lack of liquidity in the

\footnotetext{
${ }^{38}$ The method involves using sorting stocks size-based quintiles and computing the 99th stock price percentile. Small trades are trades whose dollar values are less than defined as one hundred times this percentile, and large trades are defined as those exceeding 200 times the percentile. Imbalances are market-adjusted by subtracting the market-wide aggregate imbalance for each trade category. See Hvidkjaer (2006) for details.

${ }^{39}$ For brevity we do not report results for the mild periods, which are available from the authors upon request.
} 
marketplace. If institutions cannot offload the desired volume of losers during the formation period, some of their selling will be postponed.

In pessimistic periods the trades of smaller investors among loser stocks are generally of the same sign as in optimistic periods, but different in terms of magnitude. Specifically, small investors are less inclined to buy losers in the formation period and, again, delay their selling until the holding period. The order imbalances of large investors are strikingly different. In the formation period they do not exhibit any significant selling pressure for loser stocks and, interestingly, exhibit buying pressure for both winners and losers in the holding period. This suggests that large investors are aware of the general adverse effect of pessimistic sentiment on stock prices and time their buying behavior accordingly. By doing so they actively arbitrage the winning stocks to counteract the effects of cognitive dissonance in such stocks during pessimistic periods. $^{40}$

The order flow analysis indicates that smaller investors are net buyers of losers in the formation period, and only start to sell these stocks deep into the holding period, prolonging the pricing of bad news. On the contrary, large investors are strong sellers of losing stocks in the formation period, suggesting that they promptly react to negative information. The evidence thus supports the view that smaller investors display stronger evidence of cognitive dissonance and play a key role in contributing to momentum during periods of optimistic sentiment.

We now use the order flow data to provide more direct evidence on the reactions of small and large investors to negative information in the loser portfolio, conditional on sentiment. Specifically, we calculate the average daily order imbalance for large and small investors following strong negative earnings surprises, where the latter are defined as in Table 11.

The results are shown in Table 13. Focusing on small investors, we observe that the selling pressure during the event period is stronger when sentiment is pessimistic than optimistic $(-4.1 \%$ vs. $-1.7 \%)$. Although the difference is not statistically significant, the point estimate of

\footnotetext{
${ }^{40}$ This result may be reinforced by portfolio rebalancing; specifically, since both winners and losers lose value in pessimistic periods, institutions may become net buyers to restore their appropriate weight in a standard asset allocation setting [e.g., Merton (1971)].
} 
the selling pressure is consistent with cognitive dissonance as small investors react more promptly to negative earnings surprises when they are pessimistic. The adjustment period results show that small investors exert delayed selling pressure, of roughly equal magnitude in optimistic and pessimistic periods. However, it is noteworthy that in optimistic periods the adjustment-period selling pressure is four times higher (and statistically different) from the selling pressure in the event period, which provides supplemental support to the notion that small investors respond sluggishly to bad news when they are optimistic.

The results for large investors (Panel B) tell a completely different story. Large investors sell losers with bad news four times more heavily when sentiment is optimistic than pessimistic in the event period (-9\% vs. $-2 \%)$. This finding suggests that large investors are able to time the market and sell more aggressively when sentiment is optimistic. In the adjustment period, when sentiment is optimistic, large investors continue to sell losers at roughly the same rate, whereas in pessimistic periods their average order flow is neutral $(-8 \%$ vs. $0 \%)$.

The results in this section provide additional support to the claim that cognitive dissonance is mainly ingrained in the trades of small investors, who tend to delay the pricing of bad news in the loser portfolio when sentiment is optimistic. Large investors, on the other hand, seem to take into account the general effect of sentiment on the pricing level, and sell losers with bad news more aggressively when sentiment is optimistic.

\subsection{Momentum Profits, Sentiment, and Long-Run Returns}

A central prediction of behavioral theories such as Hong and Stein (1999) and Daniel, Hirshleifer, and Subrahmanyam (1998) is that momentum profits revert in the long run. Since we document that momentum profits are only significant when investors are optimistic, it is worth examining whether these profits reverse over longer horizons. In this section, we examine the pattern of momentum profits in event time, five years after portfolio formation.

Table 14 presents the results. As expected, momentum profits revert only after optimistic periods, regardless of whether returns are risk-adjusted. For portfolios constructed in optimistic sentiment states using raw returns, this reversal, as shown in Panel A, is equal to an average 
monthly return of $-0.49 \%$. The corresponding figure in subsequent panels for CAPM (FF)adjusted returns is $-0.49 \%(-0.38 \%)$. However, for portfolios formed in pessimistic periods, as expected, there is no reversal. The momentum returns are equal to $-0.06 \%$ and $-0.04 \%$ for raw and CAPM adjusted returns respectively, and $0.13 \%$ for Fama-French adjusted returns.

A noteworthy result in Table 14 is that while mild sentiment portfolios experience marginally significant reversals for raw $(-0.17 \%)$ or CAPM-adjusted $(-0.17 \%)$ returns, these profits become insignificant when they are adjusted using the Fama-French 3 factor model $(0.01 \%)$. This result suggests that the reversal in the mild sentiment portfolio is related to the HML and/or SMB factor, and thus is not abnormal in the context of the 3-factor model. This finding is in line with Fama and French (1996), who show that the 3-factor model is able to price the long-run reversals documented by De Bondt and Thaler (1985). However, reversals in the optimistic momentum portfolios survive the Fama and French (1993) risk controls. ${ }^{41}$

Another striking feature is that, regardless of the risk adjustment technique, the monotonic pattern in the short-run returns of the optimistic momentum portfolios completely reverts in the long run as in this case, returns decrease as one moves from loser to winner portfolios. A similar, albeit less pronounced, pattern is seen in mild sentiment periods. On the contrary, however, the long-run returns of the pessimistic momentum portfolios exhibit no such pattern. Thus, our findings reveal an important link between short-run momentum and long-run reversal, showing that they commonly arise primarily when winner-loser portfolios are formed during periods of positive sentiment. ${ }^{42}$

\footnotetext{
${ }^{41} \mathrm{We}$ also perform a regression similar to Table 4, Panel C, where the dependent variable is the long-term momentum portfolio (as described in Table 14). In the regression, the stock market variables are not significant, whereas the coefficient on our sentiment variable is negative and strongly significant. This further supports the notion that momentum profits after high sentiment periods reverse more strongly in the long run.

${ }^{42}$ Cooper, Gutierrez, and Hameed (2004) and Lee and Swaminathan (2000) also document links between short-term momentum and long-term reversals. The former authors show that momentum profits revert after UP markets, where short-run momentum is significant. However, they also find that momentum profits revert after DOWN markets, and the difference in the reversals between UP and DOWN markets is not significant. Lee and Swaminathan (2000) find that trading volume also predicts reversals, albeit differently for winners and losers. Specifically, they find that momentum portfolios comprised of high volume winners and low volume losers exhibit reversals, whereas the opposite classifications result to continuations. Our study complements these papers by showing that an exogenous measure of optimism, namely, sentiment, predicts a significant difference in the long-run performance of momentum portfolios.
} 


\section{Concluding Remarks}

As price momentum is an important phenomenon in stock returns that is not captured by the Fama and French (1996) three-factor model, it is worthy of analysis from different perspectives. In this paper, we examine the relationship between price momentum and sentiment. Our hypothesis is that bad news diffuses particularly slowly during periods of optimism, as negative news causes cognitive dissonance in optimistic investors. Our analysis indicates that momentum profits are significant only when investors are optimistic (i.e., when the sentiment measure is high). This result is robust to firm size, analyst coverage, market states, risk adjustments, and alternative specifications for investor sentiment.

We calculate net order flows using transactions data and show that smaller (and presumably less sophisticated) investors are reluctant to sell losing stocks in optimistic periods. On the contrary, large investors are more prompt sellers of losers in optimistic periods. This result is in line with the notion that small investors are afflicted with cognitive dissonance when confronted with losing stocks in periods of positive sentiment. In addition, we show that longrun price reversals occur only after optimistic periods. This is consistent with the idea that the actions of "momentum traders" exacerbate price continuations during optimistic periods, and subsequently, prices correct towards fundamentals, as argued by Hong and Stein (1999).

The recent findings of Chui, Titman, and Wei (2010), show that momentum is more pronounced in individualistic cultures. This raises the question of whether the asymmetric momentum pattern we have documented for the U.S., where individualistic attitudes are considered to be higher than in other cultures, gains support in countries characterized by less individualism. Exploration of this issue would seem to be an interesting area for future research. 


\section{References}

Acemoglu, D., Scott, A., 1994, Consumer confidence and rational expectations: Are agents beliefs consistent with the theory?, Economic Journal, 104, 1-19.

Arkes, H., Herren, L., Isen, A., 1988, The role of potential loss in the influence of affect on risk taking behavior, Organizational Behavior and Human Decision Processes, 35, 124-140.

Asness, C., Moskowitz, T., Pedersen, L., 2009, Value and momentum everywhere, working paper, New York University.

Baker, M., Wurgler,. J., 2006, Investor sentiment and the cross-section of stock returns, Journal of Finance, 61, 1645-1680.

Baker, M., Wurgler, J., 2007, Investor sentiment in the stock market, Journal of Economic Perspectives, 21, 129-152.

Bergman, N., Roychowdhury, S., 2008, Investor sentiment and corporate disclosure, Journal of Accounting Research, 45, 1057-1083.

Bower, G., 1981, Mood and memory, American Psychologist, 36, 129-148.

Bower, G., 1991, Mood congruity of social judgment, in J. Forgas (Ed.) Emotion and Social Judgment, Oxford, England: Pergamon Press.

Bracha, A., Brown, D., 2010, Affective decision-making: A theory of optimism-bias, Cowles Foundation discussion paper No. 1759, Yale University.

Brown, W., Cliff, M., 2005, Investor sentiment and asset valuation, Journal of Business, 78, 405439. 
Brunnermeier, M., Parker, J., 2005, Optimal expectations, American Economic Review, 95, 1092-1118.

Chan, L., Jegadeesh, N., Lakonishok, J., 1996, Momentum strategies, Journal of Finance, 51, 1681-1713.

Charoenrook, A., 2003, Does sentiment matter?, working paper, Vanderbilt University.

Chordia, T., Roll, R., Subrahmanyam, A., 2002, Order imbalance, liquidity, and market returns, Journal of Financial Economics, 65, 111-130.

Chordia, T.,Shivakumar, L., 2002, Momentum, business cycle, and time-varying expected returns," Journal of Finance, 57, 985-1019.

Chui, A, Titman, S., Wei., J., 2010, Individualism and momentum around the world, Journal of Finance, 65, 361-392.

Conrad, J., Kaul, G., 1998, An anatomy of trading strategies, Review of Financial Studies, 11, 489-519.

Cooper, M., Gutierrez, C. Jr., Hameed, A., 2004, Market states and momentum, Journal of Finance, 49, 1345-1365.

Cornelli, F., Goldreich, D., Ljungqvist, A., 2006, Investor sentiment and Pre-IPO markets, Journal of Finance, 61, 1187-1216.

D'Avolio, G., 2002, The market for borrowing stock, Journal of Financial Economics, 66, 271306.

Daniel, K., Hirshleifer, D., Subrahmanyam, A., 1998, Investor psychology and security market under-and overreactions, Journal of Finance, 53, 1839-1885. 
DeBondt, W., Thaler, R., 1985, Does the stock market overreact?, Journal of Finance, 40, 793805.

Doukas, J., McKnight, P., 2005, European momentum strategies, information diffusion and investor conservatism," European Financial Management, 11, 313-338.

Edmans, A., Garcia, D., Norli, Ø., 2007, Sports sentiment and stock returns, Journal of Finance, 62, 1967-1998.

Fama, E., French, K., 1993, Common risk factors in the returns of stocks and bonds, Journal of Financial Economics, 33, 3-56.

Fama, E., French, K., 1996, Multifactor explanations of asset pricing anomalies, Journal of Finance, 51, 55-84.

Festinger, L., 1957, A Theory of Cognitive Dissonance, Stanford University Press, Stanford, CA.

Fisher, L., Statman, M., 2003, Consumer confidence and stock returns, Journal of Portfolio Management, 30, 115-127.

Frazzini, A., Lamont, O., 2008, Dumb Money: Mutual fund flows and the cross section of stock returns, Journal of Financial Economics, 88, 299-322.

Goetzmann, W., Massa, M., 2002, Daily momentum and contrarian behavior of index fund investors, Journal of Financial and Quantitative Analysis, 37, 325-389.

Grinblatt, M., Keloharju, M., 2000, The investment behavior and performance of various investor types: A study of Finland's unique data set, Journal of Financial Economics, 55, 43-67.

Grinblatt, M., Keloharju, M., 2009, Sensation seeking, overconfidence and trading activity, Journal of Finance, 64, 549-578. 
Grinblatt, M., Han, B., 2005, Prospect theory, mental accounting and momentum, Journal of Financial Economics, 78, 311-339.

Grundy, B., Martin, S., 2001, Understanding the nature of the risks and the source of the rewards to momentum investing, Review of Financial Studies, 14, 29-78.

Hirshleifer, D., Shumway, T., 2003, Good day sunshine: Stock returns and the weather, Journal of Finance, 58, 1009-1032.

Hong, H., Stein, J., 1999, A unified theory of underreaction, momentum trading, and overreaction in asset markets, Journal of Finance, 54, 2143-2184.

Hong, H., Lim, T., Stein, J., 2000, Bad news travels slowly: Size, analyst coverage, and the profitability of momentum strategies, Journal of Finance, 55, 265-295.

Hvidkjaer, S., 2006, A trade-based analysis of momentum, Review of Financial Studies, 19, 457491.

Hvidkjaer, S., 2008, Small trades and the cross-section of stock returns, Review of Financial Studies, 21, 1123-1151.

Jegadeesh, N., Titman, S., 1993, Returns to buying winners and selling losers: Implications for stock market efficiency, Journal of Finance, 48, 65-91.

Jegadeesh, N., Titman, S., 2001, Profitability of momentum strategies: An evaluation of alternative explanations, Journal of Finance, 56, 699-720.

Johnson, T., 2002, Rational momentum effects, Journal of Finance, 57, 585-608.

Johnson, E., Tversky A., 1983, Affect, generalization, and the perception of risk, Journal of Personality and Social Psychology, 45, 20-31. 
Kaplanski, G., Levy, H., 2010, Sentiment and stock prices: The case of aviation disasters, Journal of Financial Economics, 95, 174-201.

Lakonishok, J., Lee, I., Pearson, N., Poteshman, A., 2007, Option Market Activity, Review of Financial Studies, 20, 813-857.

Lakonishok, J., Shleifer, A., Vishny, R., 1994, Contrarian investment, extrapolation, and risk, Journal of Finance, 49, 1541-1578.

Lee, C., Shleifer, A., Thaler, R., Investor sentiment and the closed-end fund puzzle, Journal of Finance, 46, 75-109.

Lee, C., Swaminathan, B., 2000, Price momentum and trading volume, Journal of Finance, 55, 2017-2069.

Lemmon, M., Portniaguina, E., 2006, Consumer confidence and asset prices: Some empirical evidence, Review of Financial Studies, 19, 1499 - 1529.

Livnat, J., Petrovits, C., 2008, Investor sentiment, post-earnings announcement drift, and accruals, working paper, New York University.

Ludvigson, S., 2004, Consumer confidence and consumer spending, Journal of Economic Perspectives, 18, 29-50.

Malmendier, U., Shanthikumar, D., 2007, Are small investors naïve about incentives?, Journal of Financial Economics, 85, 457-489.

McLean, D., Zhao, M, 2009, Investor sentiment and real investment, Working Paper, University of Alberta.

Merton, R., 1971, Optimal consumption and portfolio rules in a continuous-time model, Journal 
of Economic Theory, 3, 373-413.

Moskowitz, T., Grinblatt, M., 1999, Do industries explain momentum?, Journal of Finance, 54, 1249-1290.

Nagel, S., 2005, Short sales, institutional investors, and the cross section of stock returns, Journal of Financial Economics, 78, 277-309.

Newey, W. K., West, K. D., 1987, A simple positive semi-definite heteroscedasticity and autocorrelation consistent covariance matrix, Econometrica, 55, 703-708.

Odean, T., 1999, Do investors trade too much? American Economic Review, 89, 1279-1298.

Otoo, M., 1999, Consumer sentiment and the stock market, working paper, Board of Governors of the Federal Reserve, Washington, DC.

Puri, M., Robinson, D., 2007, Optimism and economic choice, Journal of Financial Economics, $86,71-99$.

Qiu, X., L., Welch, I., 2006, Investor sentiment measures, NBER working paper No. w10794.

Rouwenhorst, G., 1998, International momentum strategies, Journal of Finance, 53, 267-284.

Slovic, P., 2000, The Perception of Risk, Earthscan Publications, London, UK.

Veldkamp, L., L., 2005, Slow boom, sudden crash, Journal of Economic Theory, 124, 230-257.

Veronesi, P., 1999, Stock market overreaction to bad news in good times: A rational expectations equilibrium model, Review of Financial Studies, 12, 975-1007.

Weinstein, N., 1980, Unrealistic optimism about future life events, Journal of Personality and 
Social Psychology, 39, 806-820.

Whaley, E., R., 2009, Understanding the VIX, Journal of Portfolio Management, 35, 98-105.

Wright, F., Bower, H., 1992, Mood effects on subjective probability assessment, Organizational Behavior and Human Decision Processes, 52, 276-291. 

Figure 1

Investor sentiment (CB) from 1966-2008

This figure plots two series. The first is the raw data of consumer confidence provided by the Conference Board. The second series is the 3-month rolling average of the residual from regressing the $\mathrm{CB}$ index series on the following set of macroeconomic variables: growth in industrial production, real growth in durable consumption, non-durable consumption, services consumption, growth in employment, and an NBER recession indicator.

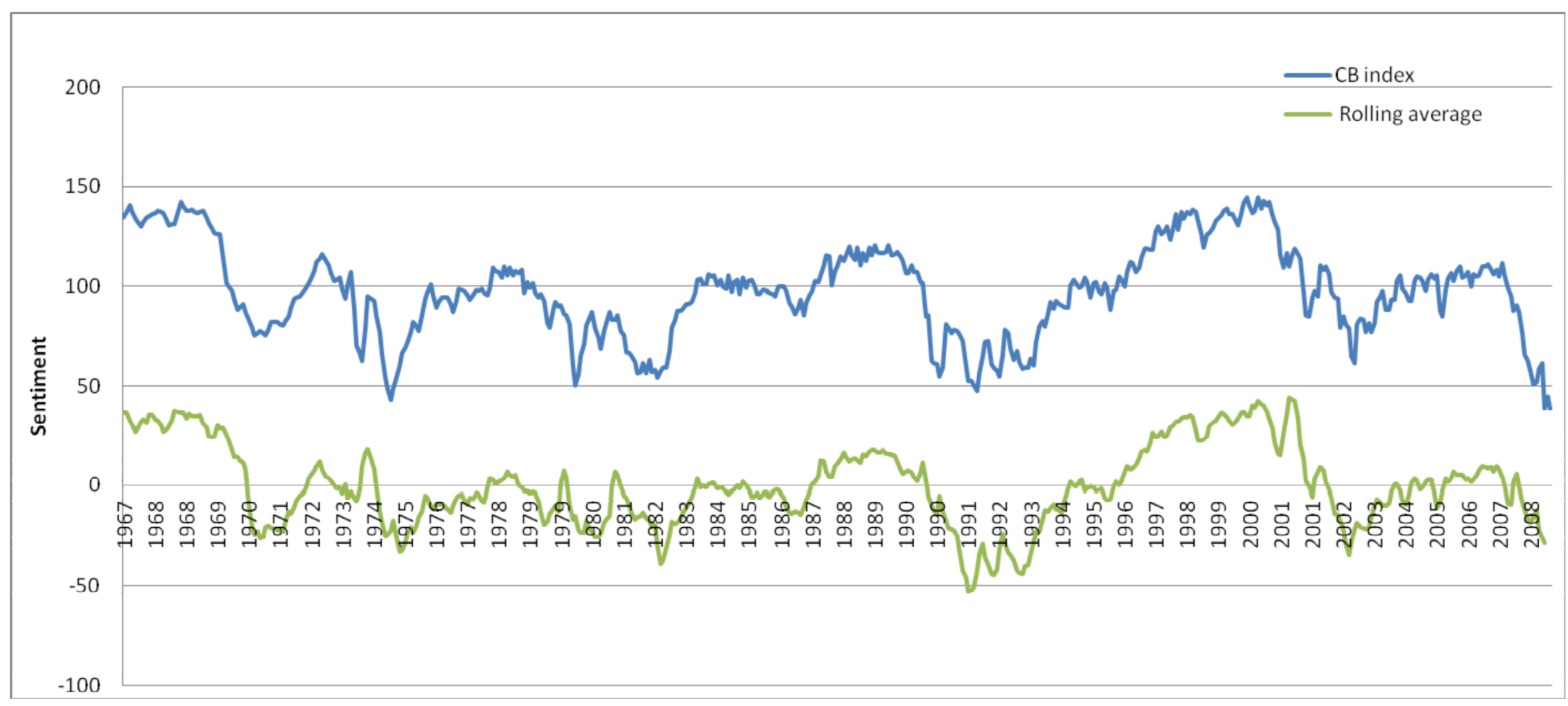




\section{Table 1 Descriptive Statistics}

Panel A presents descriptive statistics for the raw time series of consumer confidence, as compiled by Conference Board. Panel B presents the 3 month rolling average of the component of investor sentiment that is orthogonal to macroeconomic conditions. To derive this component we regress raw sentiment on growth in industrial production, real growth in durable, non-durable, and services consumption, growth in employment, and an NBER recession indicator, and then use the residuals from this regression to calculate the 3-month rolling average. The sample period is April 1967 to December 2008.

\section{Panel A: CB consumer confidence}

$\begin{array}{cccccccc}\text { Mean } & \sigma & \text { Q1 } & \text { Median } & \text { Q3 } & \text { Minimum } & \text { Maximum } & \text { N } \\ 97.40 & 23.06 & 82.59 & 98.00 & 110.60 & 38.62 & 144.71 & 501\end{array}$

Panel B: CB consumer confidence orthogonal to macroeconomic variables 
Table 2

\section{Momentum Profits Conditional on Investor Sentiment}

This table presents average monthly returns in percentages for price momentum strategies involving all NYSE/AMEX stocks for the time period April 1967 until December 2008 . At the beginning of each month all stocks are ranked based on their cumulative returns over the previous $J$ months. Portfolio 1 includes the loser stocks and portfolio 10 the winner stocks. The winner stocks are bought and the loser stocks sold, and this position is held for $K$ months. Monthly holding period returns come from overlapping strategies and are computed as an equal- weighted average of returns from strategies initiated at the beginning of this month, and the previous $K-1$ months. We allow one month between the end of the formation period and the beginning of the holding period, and delete all stocks that are priced less than one $\$ 1$ at the beginning of the holding period. Sentiment is measured using the time series of consumer confidence sentiment index constructed by the Conference Board. We regress this series on growth in industrial production, real growth in durable, non-durable, and services consumption, growth in employment, and an NBER recession indicator, and use the residuals from this regression as the sentiment proxy. In order to identify whether a particular formation period was optimistic or pessimistic, in each month $t$ we calculate the average sentiment level for the previous 3 months, using a weight of $3 / 6$ for month $\mathrm{t}$, a weight of $2 / 6$ for month $\mathrm{t}-1$ and a weight of $1 / 6$ for month t- 2 . In Panel A (B) the top $30 \%(40 \%)$ observations of this rolling average time series are the high sentiment periods, and the bottom $30 \%(40 \%)$ the low sentiment periods. To identify each holding period month as optimistic and pessimistic, we calculate how many of the $K$ formation periods were of high and low sentiment. If all $K$ formation periods were classified as optimistic (pessimistic) the holding period month is classified as optimistic (pessimistic). To test whether momentum profits in each sentiment state respectively are equal to zero, we regress the time series of average monthly momentum profits on Optimistic, Pessimistic and Mild sentiment dummies, with no intercept. To test if mean profits in Optimistic sentiment periods are different from profits in Pessimistic sentiment periods we regress average monthly momentum profits on a Mild sentiment dummy variable and an Optimistic sentiment dummy variable with a constant. The $t$-statistics of the significance of momentum profits and the difference between profits derived after optimistic and pessimistic periods are calculated using Newey-West standard errors, where the lag is set to $K-1$.

Momentum Portfolio

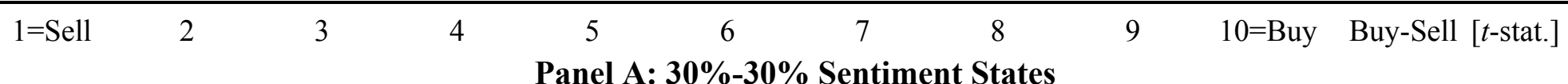

\section{Panel A1: $J=6, K=3$}

\begin{tabular}{|c|c|c|c|c|c|c|c|c|c|c|c|c|c|}
\hline Optimistic & $(n=133)$ & -0.85 & -0.05 & 0.36 & 0.53 & 0.68 & 0.78 & 0.96 & 0.90 & 1.09 & 1.42 & 2.27 & {$[5.06]$} \\
\hline Mild & $(n=246)$ & -0.24 & 0.53 & 0.81 & 0.91 & 0.97 & 1.01 & 1.04 & 1.04 & 1.14 & 1.20 & 1.44 & {$[4.67]$} \\
\hline \multirow[t]{2}{*}{ Pessimistic } & $(n=121)$ & 1.86 & 2.07 & 2.21 & 2.14 & 2.08 & 1.97 & 1.91 & 1.84 & 1.89 & 2.15 & 0.29 & {$[0.56]$} \\
\hline & & & & & & & & & & & Opt.-Pes & 1.98 & {$[2.90]$} \\
\hline \multicolumn{14}{|c|}{ Panel A2: $J, K=6$} \\
\hline Optimistic & $(n=121)$ & -0.48 & 0.17 & 0.52 & 0.67 & 0.86 & 0.95 & 1.10 & 1.10 & 1.26 & 1.51 & 2.00 & {$[5.66]$} \\
\hline Mild & $(n=286)$ & -0.28 & 0.34 & 0.63 & 0.77 & 0.86 & 0.91 & 0.99 & 1.05 & 1.12 & 1.18 & 1.46 & {$[5.66]$} \\
\hline \multirow[t]{2}{*}{ Pessimistic } & $(n=93)$ & 2.12 & 2.41 & 2.45 & 2.31 & 2.24 & 2.21 & 2.11 & 2.13 & 2.21 & 2.45 & 0.34 & {$[0.77]$} \\
\hline & & & & & & & & & & & Opt.-Pes. & 1.66 & {$[2.96]$} \\
\hline \multicolumn{14}{|c|}{ Panel A3 : $J=6, K=12$} \\
\hline Optimistic & $(n=109)$ & -0.27 & 0.20 & 0.49 & 0.62 & 0.78 & 0.86 & 0.94 & 0.96 & 1.00 & 1.00 & 1.27 & {$[3.50]$} \\
\hline Mild & $(n=337)$ & 0.38 & 0.75 & 0.95 & 1.02 & 1.10 & 1.12 & 1.18 & 1.22 & 1.25 & 1.23 & 0.85 & [4.14] \\
\hline \multirow[t]{2}{*}{ Pessimistic } & $(n=54)$ & 2.05 & 2.25 & 2.21 & 2.12 & 2.11 & 2.05 & 2.00 & 2.00 & 2.06 & 2.14 & 0.09 & {$[0.22]$} \\
\hline & & & & & & & & & & & Opt.-Pes. & 1.18 & {$[2.20]$} \\
\hline
\end{tabular}




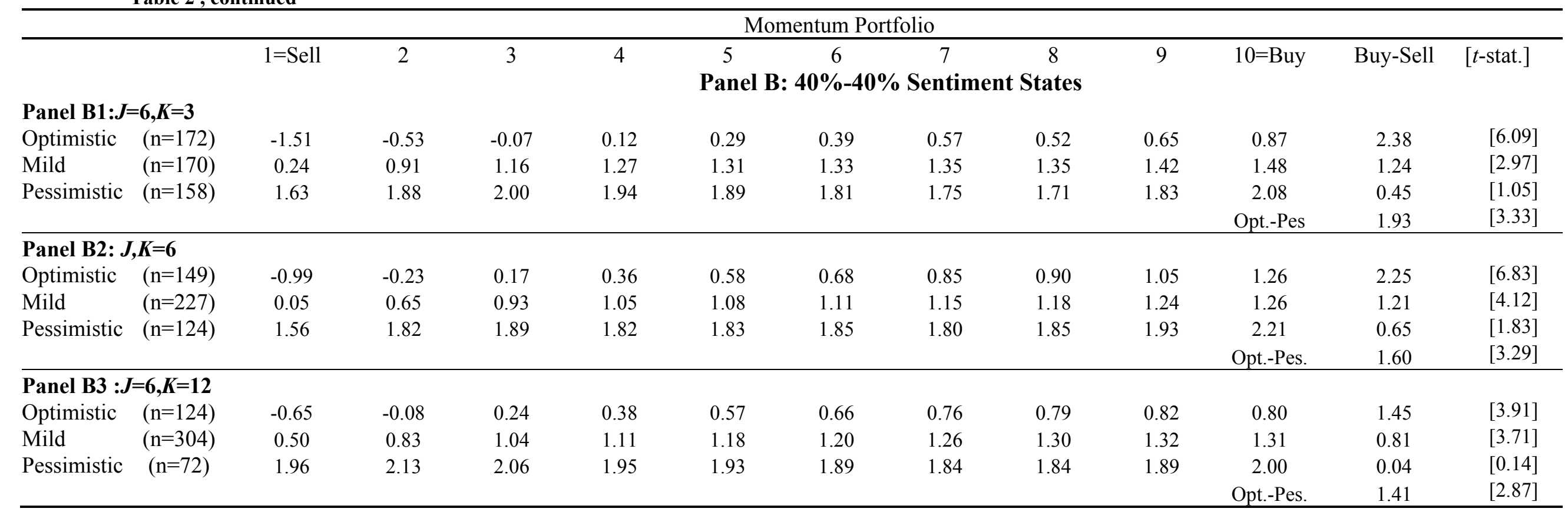


Table 3

\section{Momentum Profits Conditional on Different Market States and Investor Sentiment}

This table presents average monthly returns in percentages for price momentum strategies involving all NYSE/AMEX stocks for the time period April 1967 until December 2008. Panel A shows momentum strategies implemented in UP markets, whereas Panel B shows momentum strategies implemented after DOWN markets. The state of the market is the return of the value weighted market index including dividends 36 (Panel A1,B1), 24 (A2,B2) and 12 (A3,B3) months prior to beginning of the holding period, as measured by Cooper et al (2004). We allow one month between the end of the formation period and the holding period, and delete all stocks that are priced less than one $\$ 1$ at the beginning of the holding period. Sentiment is defined as in table 2 . To test whether momentum profits in each sentiment state respectively are equal to zero, we regress the time series of average monthly momentum profits on Optimistic, Pessimistic and Mild sentiment dummies, with no intercept. To test if mean profits in Optimistic sentiment periods are different from profits in Pessimistic sentiment periods we regress average monthly momentum profits on a Mild sentiment dummy variable and an Optimistic sentiment dummy variable with a constant. In this table the numbers of months in the pre- and post-formation periods, $J, K=6$.

Momentum Portfolio

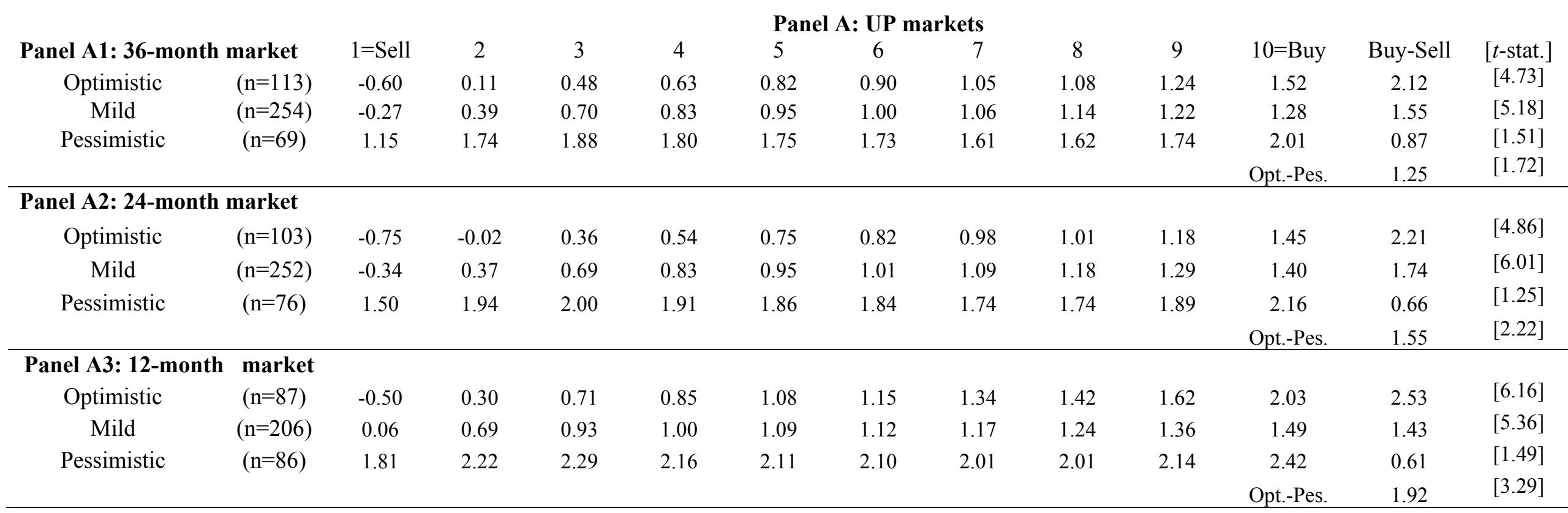


Table 3, continued

Momentum Portfolio

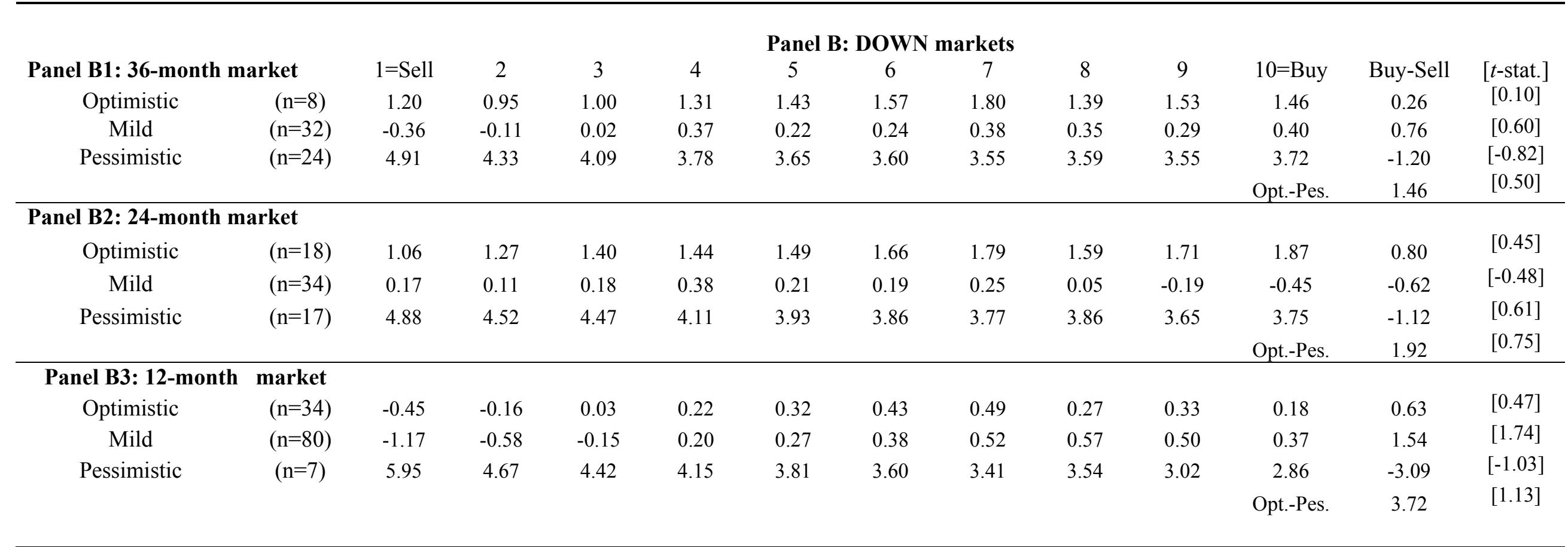


Table 4

Regressions of Momentum Profits on Market Returns and Investor Sentiment

This table presents regressions based on the regression model of Cooper, Gutierrez, and Hameed (2004) (Table V, p. 1361), augmented with investor sentiment. Market is the return of the value weighted market index 36, 24 and 12 months prior to beginning of the holding period, and Market ${ }^{2}$ is the square term of the Market. Sentiment is the 3-month weighted rolling average ending in month $t-1$ divided by 1000 . In Panel C, we define the sentiment residual by regressing raw sentiment in month $t$ on the macroeconomic variables and market returns (12 month returns in Panel 1, 24 month in Panel 2 and 36 month in Panel 3). The dependent variable is momentum profits in month $t$. The T- statistics are calculated using Newey-West standard errors, where the lag is set to $K-1$. In this table $J, K=6$.

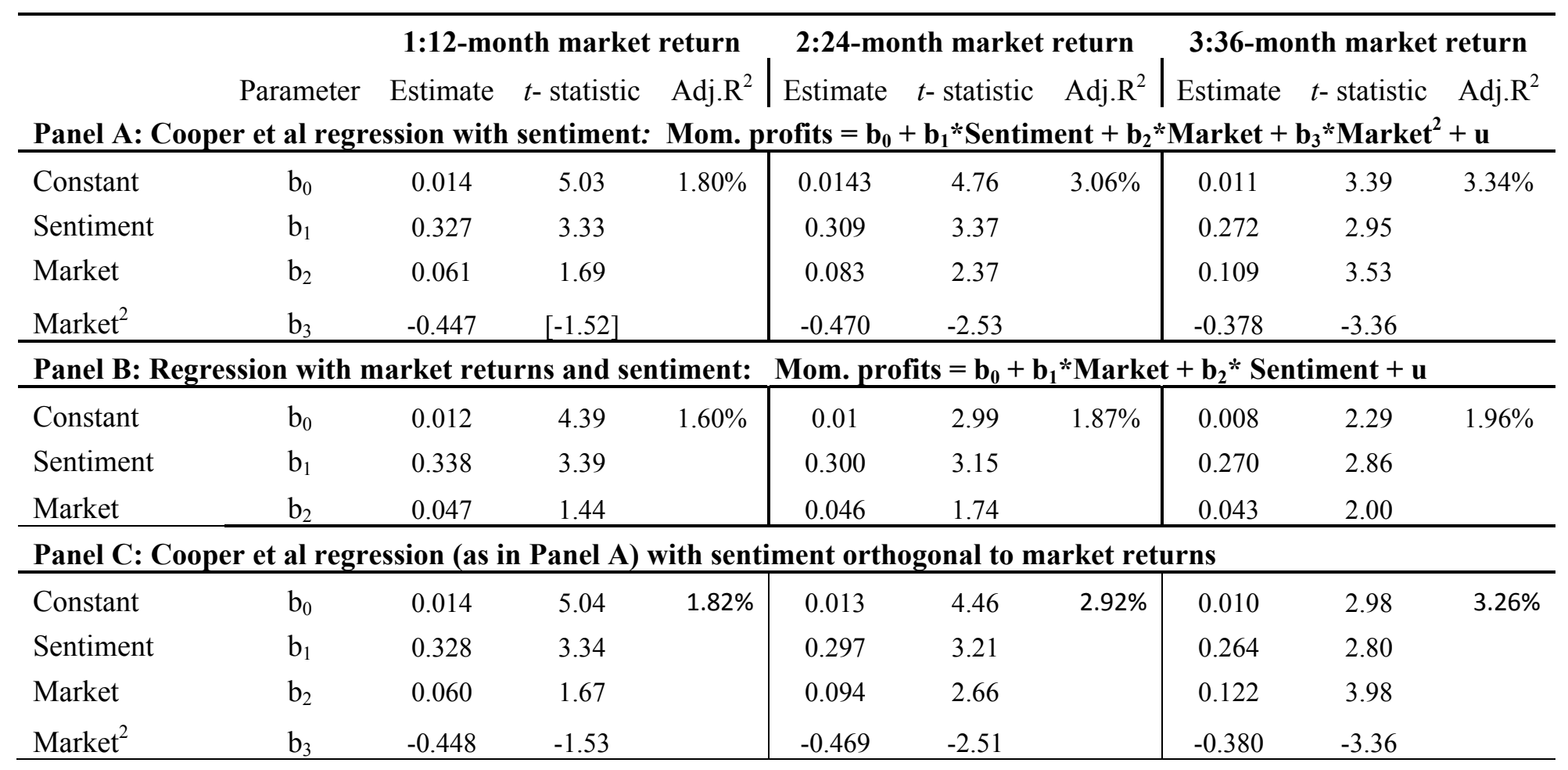


Table 5

Momentum Profits Conditional on Investor Sentiment and Analyst Coverage

This table presents average monthly returns in percentages for price momentum strategies involving all NYSE/AMEX stocks for the time period January 1980 until December 2008. The three panels shows momentum strategies implemented on the companies with low, medium, and high analyst coverage. To stratify the sample, we first perform the cross-sectional regression $\log (1+$ analysts $)=\mathrm{a}+\mathrm{b} * \log ($ size $)+e$, where analysts is the number of analysts making one-year-ahead EPS forecasts in each month $t$, and size is the market capitalization at the end of the month $t$ - 1 . Then, we form 3 groups of analyst coverage every month using the residuals $(e)$ from the above model. We allow one month between the end of the formation period and the holding period, and delete all stocks that are priced less than one $\$ 1$ at the beginning of the holding period. Sentiment is defined as in Table 2 . In this table we use $30 \%$ - $30 \%$ cut-off points for optimistic and pessimistic sentiment. To test whether momentum profits in each sentiment state respectively are equal to zero, we regress the time series of average monthly momentum profits on Optimistic, Pessimistic and Mild sentiment dummies, with no intercept. To test if mean profits in Optimistic sentiment periods are different from profits in Pessimistic sentiment periods we regress average monthly momentum profits on a Mild sentiment dummy variable and an Optimistic sentiment dummy variable with a constant. The $t$-statistics of the significance of momentum profits and the difference between profits derived after optimistic and pessimistic periods are calculated using Newey-West standard errors, where the lag is set to $K-1$. In this table the numbers of months in the pre- and postformation periods $J, K=6$.

\begin{tabular}{|c|c|c|c|c|c|c|c|c|c|c|c|c|c|}
\hline & & \multicolumn{12}{|c|}{ Momentum Portfolio } \\
\hline & & 1 & 2 & 3 & 4 & 5 & 6 & 7 & 8 & 9 & $10=$ Buy & Buy-Sell & {$[t$-stat. $]$} \\
\hline \multicolumn{14}{|c|}{ Panel A:Low coverage (mean $=2.57$ analysts) } \\
\hline Optimistic & $(n=77)$ & -0.94 & 0.05 & 0.65 & 0.79 & 0.86 & 0.98 & 1.04 & 0.96 & 1.15 & 1.26 & 2.19 & {$[4.32]$} \\
\hline Mild & $(n=200)$ & -0.83 & 0.12 & 0.45 & 0.66 & 0.85 & 0.94 & 0.97 & 1.04 & 1.08 & 1.20 & 2.03 & \multirow{3}{*}{$\begin{array}{l}{[0.02]} \\
{[2.37]} \\
\end{array}$} \\
\hline \multirow[t]{2}{*}{ Pessimistic } & $(n=71)$ & 1.56 & 2.20 & 2.24 & 2.16 & 2.03 & 2.11 & 1.84 & 1.94 & 2.13 & 2.05 & 0.49 & \\
\hline & & & & & & & & & & & Opt.-Pes & 1.70 & \\
\hline \multicolumn{14}{|c|}{ Panel B: Mid coverage (mean $=6.48$ analysts) } \\
\hline Optimistic & $(n=77)$ & -0.48 & 0.41 & 0.79 & 0.78 & 1.02 & 0.97 & 1.03 & 1.08 & 1.17 & 1.53 & 2.01 & \multirow{4}{*}{$\begin{array}{l}{[4.28]} \\
{[4.31]} \\
{[0.70]} \\
{[2.44]}\end{array}$} \\
\hline Mild & $(n=200)$ & -0.43 & 0.25 & 0.65 & 0.80 & 0.94 & 1.01 & 1.04 & 1.09 & 1.07 & 0.93 & 1.35 & \\
\hline \multirow[t]{2}{*}{ Pessimistic } & $(n=71)$ & 2.11 & 2.18 & 2.25 & 2.15 & 2.07 & 1.98 & 2.01 & 1.97 & 2.01 & 2.46 & 0.35 & \\
\hline & & & & & & & & & & & Opt.-Pes. & 1.66 & \\
\hline \multicolumn{14}{|c|}{ Panel $\mathrm{C}:$ High coverage (mean $=10.42$ analysts) } \\
\hline Optimistic & $(\mathrm{n}=77)$ & -0.17 & 0.51 & 0.67 & 0.78 & 0.93 & 0.97 & 1.21 & 1.24 & 1.28 & 1.66 & 1.83 & \multirow{2}{*}{$\begin{array}{l}{[3.37]} \\
{[5.20]}\end{array}$} \\
\hline Mild & $(n=200)$ & -0.36 & 0.33 & 0.64 & 0.67 & 0.82 & 0.89 & 0.91 & 0.99 & 1.10 & 1.30 & 1.66 & \\
\hline \multirow[t]{2}{*}{ Pessimistic } & $(n=71)$ & 2.42 & 2.51 & 2.48 & 2.23 & 2.29 & 2.21 & 2.08 & 2.06 & 2.16 & 2.43 & 0.02 & \multirow{2}{*}{$\begin{array}{l}{[0.03]} \\
{[2.26]}\end{array}$} \\
\hline & & & & & & & & & & & Opt.-Pes. & 1.81 & \\
\hline
\end{tabular}


Table 6

Momentum Profits Conditional on Investor Sentiment and Firm Size

This table presents average monthly returns in percentages for price momentum strategies involving all NYSE/AMEX stocks for the time period April 1967 until December 2008. Panel A shows momentum strategies implemented on the companies in the smaller five size deciles (Panel A) and the larger five size deciles (Panel B). Size is measured as price x shares outstanding at the end of the formation period. Size decile breakpoints are from Kenneth French's data library. We allow one month between the end of the formation period and the holding period, and delete all stocks that are priced less than one $\$ 1$ at the beginning of the holding period. Sentiment is defined as in Table 2. In this table we use 30\%-30\% cut-off points for optimistic and pessimistic sentiment. To test whether momentum profits in each sentiment state respectively are equal to zero, we regress the time series of average monthly momentum profits on Optimistic, Pessimistic and Mild sentiment dummies, with no intercept. To test if mean profits in Optimistic sentiment periods are different from profits in Pessimistic sentiment periods we regress average monthly momentum profits on a Mild sentiment dummy variable and an Optimistic sentiment dummy variable with a constant. The $t$-statistics of the significance of momentum profits and the difference between profits derived after optimistic and pessimistic periods are calculated using Newey-West standard errors, where the lag is set to $K-1$. In this table the numbers of months in the pre- and post-formation periods $J$, $K=6$.

\begin{tabular}{|c|c|c|c|c|c|c|c|c|c|c|c|c|}
\hline \multicolumn{13}{|c|}{ Momentum Portfolio } \\
\hline & $1=$ Sell & 2 & 3 & 4 & 5 & 6 & 7 & 8 & 9 & $10=$ Buy & Buy-Sell & {$[t$-stat. $]$} \\
\hline \multicolumn{13}{|l|}{ Panel A:Small Cap. } \\
\hline Optimistic $\quad(n=121)$ & -0.67 & 0.07 & 0.36 & 0.62 & 0.84 & 0.90 & 1.08 & 1.11 & 1.28 & 1.47 & 2.14 & \multirow{2}{*}{$\begin{array}{l}{[6.16]} \\
{[6.48]}\end{array}$} \\
\hline Mild $\quad(n=286)$ & -0.48 & 0.20 & 0.54 & 0.74 & 0.89 & 0.99 & 1.06 & 1.16 & 1.24 & 1.23 & 1.72 & \\
\hline \multirow[t]{2}{*}{ Pessimistic $\quad(n=93)$} & 2.13 & 2.51 & 2.65 & 2.65 & 2.55 & 2.51 & 2.48 & 2.52 & 2.52 & 2.58 & 0.46 & \multirow{2}{*}{$\begin{array}{l}{[0.88]} \\
{[2.69]} \\
\end{array}$} \\
\hline & & & & & & & & & & Opt.-Pes. & 1.68 & \\
\hline \multicolumn{13}{|l|}{ Panel B:Large Cap. } \\
\hline Optimistic $\quad(n=121)$ & 0.35 & 0.60 & 0.73 & 0.85 & 0.78 & 0.87 & 0.96 & 0.86 & 1.05 & 1.21 & 0.86 & \multirow{4}{*}{$\begin{array}{l}{[2.17]} \\
{[3.05]} \\
{[0.60]} \\
{[1.01]}\end{array}$} \\
\hline Mild $\quad(n=286)$ & 0.22 & 0.55 & 0.69 & 0.75 & 0.80 & 0.77 & 0.81 & 0.86 & 0.96 & 1.03 & 0.81 & \\
\hline Pessimistic $\quad(n=93)$ & 1.80 & 1.87 & 1.87 & 1.91 & 1.80 & 1.64 & 1.67 & 1.62 & 1.72 & 2.07 & 0.26 & \\
\hline & & & & & & & & & & Opt.-Pes. & 0.60 & \\
\hline
\end{tabular}



Table 7

Risk-adjusted Momentum Profits Conditional on Investor Sentimen

This table presents risk adjusted momentum profits calculated from CAPM, Fama-French and Conditional CAPM models. For each momentum portfolio and holding period month we form a time series of returns, which we regress on excess market return when we risk adjust according to the CAPM, and excess market return, the SMB and HML factors when we risk adjust according to the Fama-French 3 factor model. For the CCAPM we allow beta to differ depending on the average sentiment in the 6 formation periods that correspond to each portfolio return observation (see equation 3). Using these loadings and the factor realizations in each month, we estimate the monthly excess return for each portfolio. The data on market returns, the risk free rate and the SMB and HML factors are from Kenneth French's data library. Sentiment is defined as in Table 2. In this table we use 30\%-30\% cut-off points for optimistic and pessimistic sentiment. To test whether momentum profits in each sentiment state respectively are equal to zero, we regress the time series of average monthly momentum profits on Optimistic, Pessimistic and Mild sentiment dummies, with no intercept. To test if mean profits in Optimistic sentiment periods are different from profits in Pessimistic sentiment periods we regress average monthly momentum profits on a Mild sentiment dummy variable and an Optimistic sentiment dummy variable with a constant. The t-statistics of the significance of momentum profits and the difference between profits derived after optimistic and pessimistic periods are calculated using Newey-West standard errors, where the lag is set to $K-1$. In this table the numbers of months in the pre- and post-formation periods $J, K=6$.

\begin{tabular}{|c|c|c|c|c|c|c|c|c|c|c|c|c|c|}
\hline \multicolumn{14}{|c|}{ Momentum Portfolio } \\
\hline & & $1=$ Sell & 2 & 3 & 4 & 5 & 6 & 7 & 8 & 9 & $10=$ Buy & Buy-Sell & [t-stat.] \\
\hline \multicolumn{14}{|c|}{ Panel A:CAPM } \\
\hline Optimistic & $(n=121)$ & -0.83 & -0.13 & 0.24 & 0.41 & 0.61 & 0.69 & 0.85 & 0.84 & 0.98 & 1.20 & 2.03 & {$[5.46]$} \\
\hline Mild & $(\mathrm{n}=286)$ & -0.52 & 0.14 & 0.44 & 0.60 & 0.69 & 0.75 & 0.82 & 0.87 & 0.93 & 0.97 & 1.49 & {$[5.93]$} \\
\hline \multirow[t]{2}{*}{ Pessimistic } & $(n=93)$ & 0.72 & 1.22 & 1.34 & 1.25 & 1.22 & 1.20 & 1.10 & 1.09 & 1.11 & 1.21 & 0.48 & {$[1.10]$} \\
\hline & & & & & & & & & & & Opt.-Pes. & 1.55 & {$[2.68]$} \\
\hline \multicolumn{14}{|l|}{ Panel B:FF } \\
\hline Optimistic & $(\mathrm{n}=121)$ & -0.87 & -0.25 & 0.10 & 0.26 & 0.47 & 0.55 & 0.71 & 0.72 & 0.90 & 1.21 & 2.08 & {$[5.39]$} \\
\hline Mild & $(n=286)$ & -0.82 & -0.14 & 0.19 & 0.35 & 0.47 & 0.53 & 0.61 & 0.67 & 0.74 & 0.80 & 1.61 & {$[6.83]$} \\
\hline \multirow[t]{2}{*}{ Pessimistic } & $(n=93)$ & -0.46 & 0.18 & 0.39 & 0.36 & 0.39 & 0.42 & 0.33 & 0.35 & 0.40 & 0.51 & 0.96 & {$[2.30]$} \\
\hline & & & & & & & & & & & Opt.-Pes. & 1.12 & [1.95] \\
\hline \multicolumn{14}{|c|}{ Panel C: Conditional CAPM } \\
\hline Optimistic & $(n=121)$ & -0.83 & -0.12 & 0.25 & 0.41 & 0.61 & 0.70 & 0.85 & 0.84 & 0.99 & 1.20 & 2.03 & {$[5.46]$} \\
\hline Mild & $(n=286)$ & -0.52 & 0.13 & 0.43 & 0.59 & 0.68 & 0.74 & 0.81 & 0.87 & 0.92 & 0.96 & 1.48 & [5.92] \\
\hline \multirow[t]{2}{*}{ Pessimistic } & $(n=93)$ & 0.64 & 1.09 & 1.19 & 1.09 & 1.06 & 1.04 & 0.95 & 0.95 & 0.98 & 1.11 & 0.47 & {$[1.07]$} \\
\hline & & & & & & & & & & & Opt.-Pes. & 1.56 & {$[2.70]$} \\
\hline
\end{tabular}


Table 8

Momentum Profits Conditional on Sentiment Orthogonal to Current, Future Macroeconomic Conditions, and VIX

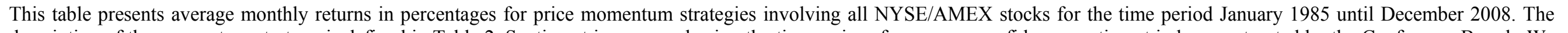

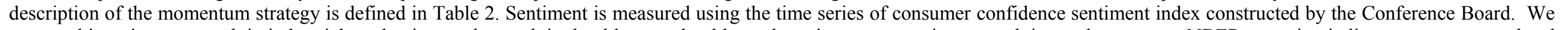

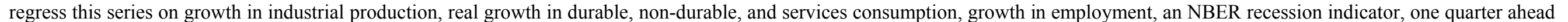

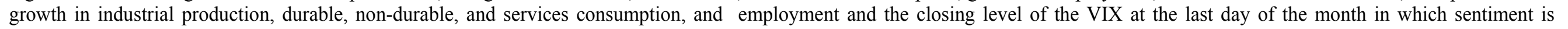

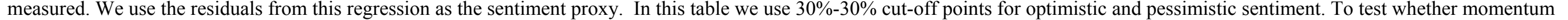

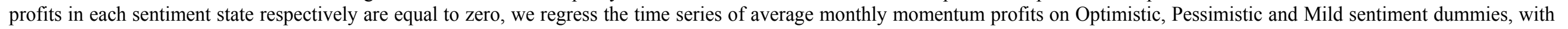

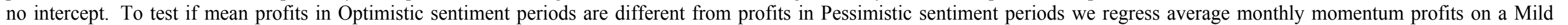

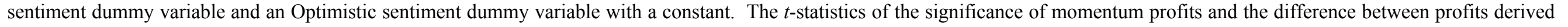

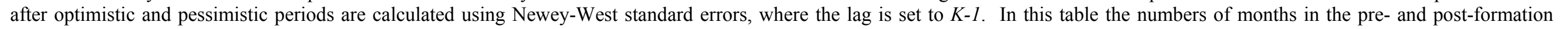
periods $J, K=6$.

\begin{tabular}{|c|c|c|c|c|c|c|c|c|c|c|c|c|c|}
\hline & \multicolumn{13}{|c|}{ Momentum Portfolio } \\
\hline & & $1=$ Sell & 2 & 3 & 4 & 5 & 6 & 7 & 8 & 9 & $10=$ Buy & Buy-S & tat.] \\
\hline Optimistic & $(n=54)$ & -1.44 & -0.47 & 0.06 & 0.27 & 0.48 & 0.52 & 0.72 & 0.68 & 0.84 & 0.98 & 2.42 & [4.34] \\
\hline Mild & $(n=167)$ & -0.53 & 0.26 & 0.58 & 0.68 & 0.79 & 0.86 & 0.88 & 0.88 & 0.90 & 0.99 & 1.51 & {$[4.73]$} \\
\hline Pessimistic & $(n=51)$ & 1.88 & 1.88 & 1.82 & 1.73 & 1.69 & 1.66 & 1.61 & 1.67 & 1.82 & 2.15 & 0.27 & {$[0.43]$} \\
\hline & & & & & & & & & & & Opt.-Pes. & 2.15 & {$[2.52]$} \\
\hline
\end{tabular}


Table 9

Momentum Profits Conditional on an Alternative Investor Sentiment Index

This table presents average monthly returns in percentages for price momentum strategies involving all NYSE/AMEX stocks for the time period October 1965 until December 2007 The momentum strategy is defined in table 2. Sentiment is measured using the monthly sentiment index constructed by Baker and Wurgler (2007), using trading volume (measured as total NYSE turnover), dividend premium, closed-end fund discount, number and first day returns in IPO's, and the equity share in new issues. Because these variables are partly related to economic fundamentals, Baker and Wurgler regress each proxy against growth in industrial production, real growth in durable, non-durable, and services consumption, growth in employment, and an NBER recession indicator, and use the residuals from this regression as the sentiment proxies. The overall sentiment index is the first principal component of the six sentiment proxies. In order to identify whether a particular formation period was optimistic or pessimistic we follow the same procedure as that outlined in Table 2. In this table we use 30\%-30\% cut-off points for optimistic and pessimistic sentiment and we group the Mild sentiment and Optimistic sentiment categories together. To test whether momentum profits in each sentiment state respectively are equal to zero, we regress the time series of average monthly momentum profits on an Optimistic sentiment dummy variable and a Pessimistic sentiment dummy variable, with no intercept. To test if mean profits in Optimistic sentiment periods are different from profits in Pessimistic sentiment periods we regress average monthly momentum profits on an Optimistic sentiment dummy variable with a constant. The t-statistics of the significance of momentum profits and the difference between profits derived after optimistic and pessimistic periods are calculated using Newey-West standard errors, where the lag is set to $K-1$. In this table the numbers of months in the pre- and post-formation periods $J$, $K=6$.

\begin{tabular}{|c|c|c|c|c|c|c|c|c|c|c|c|c|c|}
\hline \multicolumn{14}{|c|}{ Momentum Portfolio } \\
\hline & & $1=$ Sell & 2 & 3 & 4 & 5 & 6 & 7 & 8 & 9 & $10=$ Buy & Buy-Se & [t-stat. $]$ \\
\hline Optimistic & $(n=387)$ & -0.18 & 0.47 & 0.76 & 0.88 & 0.98 & 1.04 & 1.1 & 1.14 & 1.25 & 1.4 & 1.59 & [7.69] \\
\hline \multirow[t]{2}{*}{ Pessimistic } & $(n=120)$ & 2.31 & 2.34 & 2.29 & 2.21 & 2.11 & 2.04 & 2.1 & 2.15 & 2.28 & 2.61 & 0.30 & {$[0.21]$} \\
\hline & & & & & & & & & & & Opt.-Pes. & 1.29 & [2.86] \\
\hline
\end{tabular}


Table 10

Momentum Profits Conditional on Different Specifications of Investor Sentiment

This table presents average monthly returns in percentages for price momentum strategies involving all NYSE/AMEX stocks for the time period April 1967 until December 2008. We allow one month between the end of the formation period and the holding period, and delete all stocks that are priced less than one $\$ 1$ at the beginning of the holding period. Sentiment is defined as in Table 2. In this table we use 30\%-30\% cut-off points for optimistic and pessimistic sentiment. In order to identify whether a particular formation period was optimistic or pessimistic, in each month $t$ we calculate the average sentiment level for the previous 2 (Panel A) and 4 (Panel B) months. To test whether momentum profits in each sentiment state respectively are equal to zero, we regress the time series of average monthly momentum profits on Optimistic, Pessimistic and Mild sentiment dummies, with no intercept. To test if mean profits in Optimistic sentiment periods are different from profits in Pessimistic sentiment periods we regress average monthly momentum profits on a Mild sentiment dummy variable and an Optimistic sentiment dummy variable with a constant. The t-statistics of the significance of momentum profits and the difference between profits derived after optimistic and pessimistic periods are calculated using Newey-West standard errors, where the lag is set to $K-1$. In this table the numbers of months in the pre- and post-formation periods $J, K=6$.

\begin{tabular}{|c|c|c|c|c|c|c|c|c|c|c|c|c|c|}
\hline \multicolumn{14}{|c|}{ Momentum Portfolio } \\
\hline & & $1=$ Sell & 2 & 3 & 4 & 5 & 6 & 7 & 8 & 9 & $10=$ Buy & Buy-Sell & [t-stat. $]$ \\
\hline \multicolumn{14}{|c|}{ Panel A: Lag 2 sentiment } \\
\hline Optimistic & $(\mathrm{n}=118)$ & -0.46 & 0.19 & 0.50 & 0.66 & 0.84 & 0.93 & 1.10 & 1.10 & 1.27 & 1.49 & 1.95 & \multirow{2}{*}{$\begin{array}{l}{[5.48]} \\
{[5.73]}\end{array}$} \\
\hline Mild & $(n=294)$ & -0.25 & 0.36 & 0.66 & 0.80 & 0.89 & 0.94 & 1.00 & 1.06 & 1.11 & 1.18 & 1.42 & \\
\hline \multirow[t]{2}{*}{ Pessimistic } & $(n=89)$ & 2.14 & 2.45 & 2.47 & 2.32 & 2.26 & 2.24 & 2.16 & 2.19 & 2.32 & 2.59 & 0.46 & \multirow{2}{*}{$\begin{array}{l}{[0.99]} \\
{[2.56]} \\
\end{array}$} \\
\hline & & & & & & & & & & & Opt.-Pes. & 1.49 & \\
\hline \multicolumn{14}{|c|}{ Panel B: Lag 4 sentiment } \\
\hline Optimistic & $(n=122)$ & -0.43 & 0.23 & 0.60 & 0.76 & 0.95 & 1.03 & 1.20 & 1.18 & 1.37 & 1.66 & 2.10 & \multirow{2}{*}{$\begin{array}{l}{[5.66]} \\
{[5.25]}\end{array}$} \\
\hline Mild & $(n=280)$ & -0.30 & 0.30 & 0.61 & 0.76 & 0.85 & 0.90 & 0.96 & 1.02 & 1.05 & 1.07 & 1.37 & \\
\hline \multirow[t]{2}{*}{ Pessimistic } & $(n=97)$ & 1.97 & 2.32 & 2.33 & 2.19 & 2.13 & 2.12 & 2.04 & 2.08 & 2.23 & 2.59 & 0.62 & \multirow{2}{*}{$\begin{array}{l}{[1.69]} \\
{[2.83]}\end{array}$} \\
\hline & & & & & & & & & & & Opt.-Pes. & 1.48 & \\
\hline
\end{tabular}


Table 11. Earnings announcements and momentum

Panel A of this table presents cumulative abnormal returns for the $(-1,1)$ and $(2,60)$ intervals around negative earnings surprises for loser stocks. In each month $t$ of the sample, we rank stocks in deciles based on their cumulative return in the past 6 months and retain the companies in the bottom decile. We delete stocks priced less than $\$ 1$ at the end of month $t$. Sentiment is the 3-month rolling average of the residual defined in Table 2 ending in month $t$ using 30\% cut-off points. We then identify the stocks with an earnings announcement in month $t+1$ and perform an event study to examine the post earnings announcement drift. We use the seasonal random Walk model to compute earnings expectations, whereby the standardised unexpected earnings (SUE) is calculated as Earnings $s_{t}-$ Earnings $_{t-4} /\left(\right.$ quarter $_{\text {end }}$ price). In each year-quarter all firms are ranked into deciles according to their SUE. The bottom $30 \%$ are the negative surprise firms. In Panel A we report cumulative (raw) returns for losers with negative earnings surprises for the periods $(-1,1)$, and $(2,60)$ where date 0 is the earnings announcement date (note that the days correspond to trading days). Data on quarterly earnings announcements are from Compustat. T-statistics in Panel A are calculated using clustered standard errors on the company level. Panel B presents average monthly momentum returns following the methodology in Table 2. In Panel B1 we report returns with all stocks are included in the sample and in Panel B2 we delete stocks in the loser portfolio with a negative earnings surprise (bottom 30\% SUE) in the first 4 months of the holding period. To test whether momentum profits in each sentiment state respectively are equal to zero, we regress the time series of average monthly momentum profits on Optimistic, Pessimistic and Mild sentiment dummies, with no intercept using Newey-West standard errors, where the lag is set to $K-1$. In Panel $\mathrm{B} J, K=6$.

Panel A: Post-earnings announcement drift for loser stocks with low SUE

\begin{tabular}{|c|c|c|c|c|c|}
\hline Horizon & & & $(-1,1)$ & $(2,60)$ & \\
\hline Optimistic & & & -1.724 & -2.079 & \\
\hline Mild & & & -1.612 & 1.292 & \\
\hline Pessimistic & & & -1.105 & 8.647 & \\
\hline Optimistic-pessimistic & & & -0.619 & -10.726 & \\
\hline \multirow[t]{3}{*}{ t-stat } & & & {$[-2.26]$} & {$[-12.73]$} & \\
\hline & \multicolumn{5}{|c|}{ Panel B1: Momentum profits (all stocks) } \\
\hline & & Losers & Winners & Profits & t-stat \\
\hline Optimistic & $(n=77)$ & -0.44 & 1.485 & 1.925 & [4.17] \\
\hline Mild & $(\mathrm{n}=280)$ & -0.191 & 1.167 & 1.358 & {$[5.25]$} \\
\hline \multirow[t]{2}{*}{ Pessimistic } & $(\mathrm{n}=100)$ & 2.891 & 2.484 & -0.545 & {$[-0.64]$} \\
\hline & \multicolumn{5}{|c|}{ Panel B2: Excluding losers with low SUE } \\
\hline Optimistic & $(n=77)$ & 0.568 & 1.485 & 0.917 & {$[2.34]$} \\
\hline Mild & $(\mathrm{n}=280)$ & 0.442 & 1.167 & 0.725 & {$[3.18]$} \\
\hline Pessimistic & $(n=100)$ & 3.374 & 2.484 & -1.027 & {$[-1.34]$} \\
\hline
\end{tabular}


Table 12

Order Imbalances for Momentum Portfolios

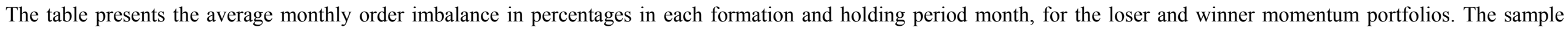

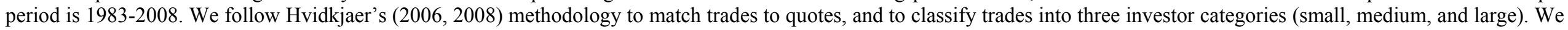

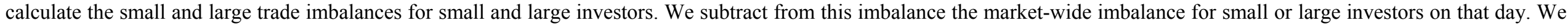

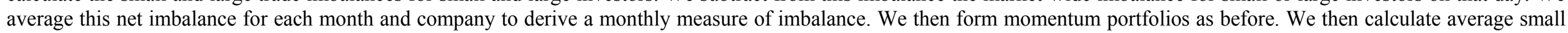

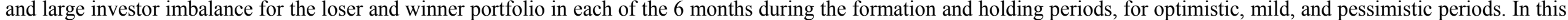

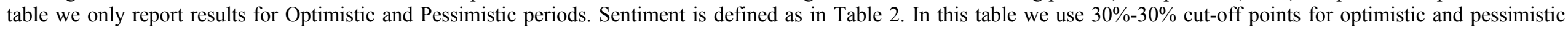
sentiment. T-statistics are in brackets.

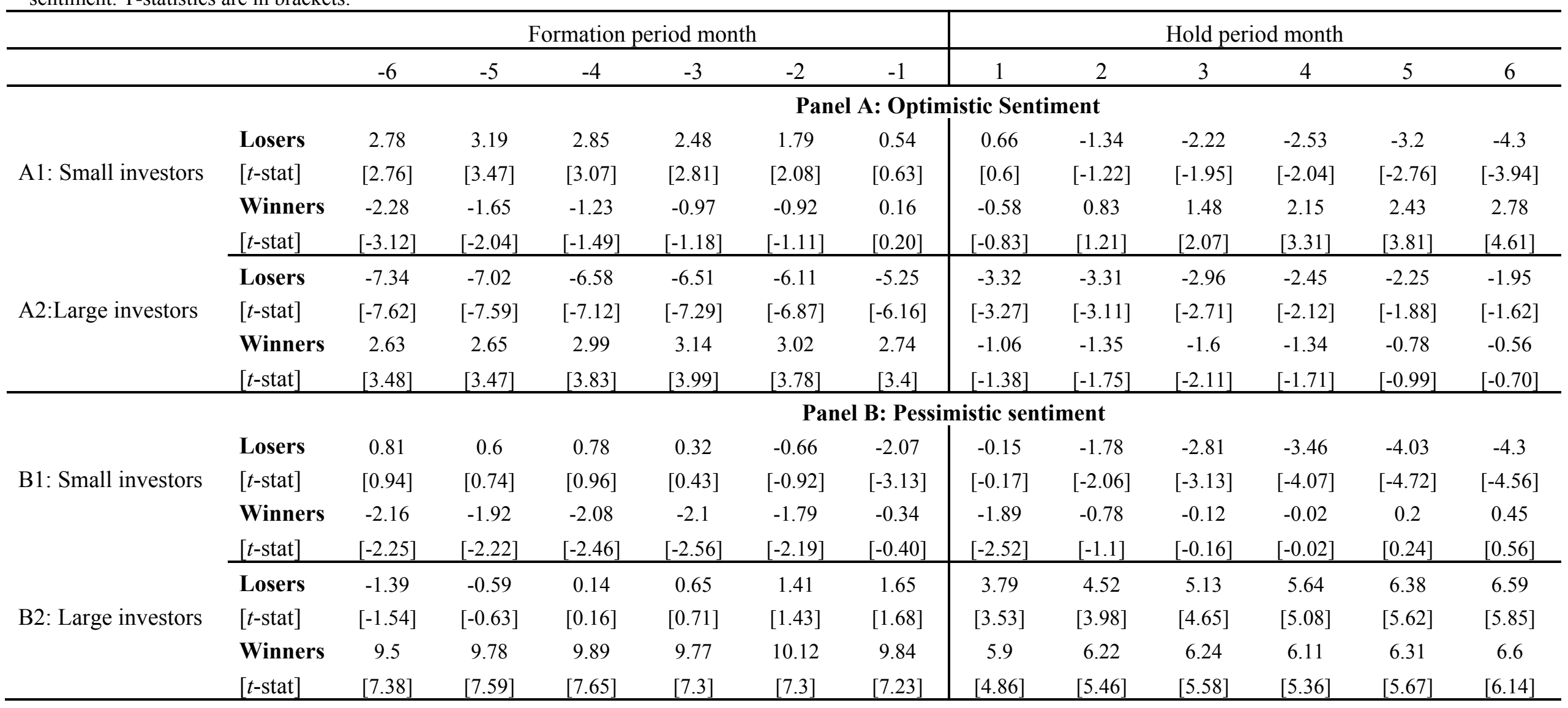


Table 13. Post-event small and large investor order imbalance for losers with low SUE

This table presents daily average order imbalance for small (Panel A) and large investors (Panel B) in percentages for the periods $(-1,1)$ and $(2,60)$, where date 0 is the event date (note that the days correspond to trading days). We follow Hvidkjaer's $(2006$, 2008) methodology to match trades to quotes, and to classify trades into three investor categories (small, medium, and large). We calculate the small and large trade imbalances for small and large investors. We subtract from this imbalance the market-wide imbalance for small or large investors on that day to obtain a daily measure of imbalance for small and large investors for each company. The event is earnings announcements, and we consider stocks in the loser portfolio with a negative earnings surprise (bottom $30 \%$ of SUE). We follow the methodology in Table 11 to calculate earnings surprises. T-statistics are in brackets and are calculated using clustered standard errors on the company level.

\begin{tabular}{|c|c|c|c|c|}
\hline Horizon & $(-1,1)$ & $(2,60)$ & & \\
\hline & & & dif. & t-stat \\
\hline \multicolumn{5}{|c|}{ Panel A: OIB for small investors } \\
\hline Optimistic & -1.70 & -7.00 & $\mathbf{5 . 3 0}$ & [5.71] \\
\hline Mild & -1.80 & -3.00 & 1.20 & [1.22] \\
\hline Pessimistic & -4.10 & -6.30 & 2.20 & {$[1.75]$} \\
\hline Optimistic-pessimistic & 2.40 & -0.70 & & \\
\hline t-stat & [1.40] & {$[-\mathbf{0 . 8 8}]$} & & \\
\hline \multicolumn{5}{|c|}{ Panel A: OIB for large investors } \\
\hline Optimistic & -9.00 & -8.00 & -1.00 & {$[-0.80]$} \\
\hline Mild & -9.00 & -4.00 & -5.00 & {$[-3.98]$} \\
\hline Pessimistic & -2.00 & 0.00 & -2.00 & {$[-0.74]$} \\
\hline Optimistic-pessimistic & -7.00 & -8.00 & & \\
\hline t-stat & {$[-3.34]$} & {$[-9.59]$} & & \\
\hline
\end{tabular}


Table 14

Long-run Profits of Momentum Portfolios Conditional on Investor Sentiment

This table presents long-run event time returns for momentum portfolios formed after optimistic and pessimistic periods. For each momentum portfolio we define an event period 13 months after the initial formation period of six months. From this event date month onwards we compute the average monthly return of this portfolio in the following 5 years. The final return of each portfolio is the geometric average of these monthly average profits. Panel A uses raw returns, Panel B CAPM adjusted returns and Panel $\mathrm{C}$ returns adjusted according to the Fama-French 3 factor model. Sentiment is defined as in Table 2 . In this table we use $30 \%-30 \%$ cut-off points for optimistic and pessimistic sentiment. To test whether momentum profits in each sentiment state respectively are equal to zero, we regress the time series of average monthly momentum profits on Optimistic, Pessimistic and Mild sentiment dummies, with no intercept. To test if mean profits in Optimistic sentiment periods are different from profits in Pessimistic sentiment periods we regress average monthly momentum profits on a Mild sentiment dummy variable and an Optimistic sentiment dummy variable with a constant. The t-statistics of the significance of momentum profits and the difference between profits derived after optimistic and pessimistic periods are calculated using Newey-West standard errors, where the lag is set to the number of overlapping strategies, which is 6.

\begin{tabular}{|c|c|c|c|c|c|c|c|c|c|c|c|c|c|}
\hline \multicolumn{14}{|c|}{ Momentum Portfolio } \\
\hline & & $1=$ Sell & 2 & 3 & 4 & 5 & 6 & 7 & 8 & 9 & $10=$ Buy & Buy-Sell & {$[t$-stat. $]$} \\
\hline \multicolumn{14}{|c|}{ Panel A: Raw } \\
\hline Optimistic & $(\mathrm{n}=121)$ & 0.81 & 0.73 & 0.70 & 0.68 & 0.67 & 0.65 & 0.62 & 0.57 & 0.49 & 0.32 & -0.49 & {$[-5.79]$} \\
\hline Mild & $(n=233)$ & 1.36 & 1.36 & 1.37 & 1.35 & 1.36 & 1.34 & 1.34 & 1.32 & 1.30 & 1.20 & -0.17 & {$[-1.86]$} \\
\hline \multirow[t]{2}{*}{ Pessimistic } & $(\mathrm{n}=91)$ & 1.13 & 1.28 & 1.29 & 1.29 & 1.30 & 1.27 & 1.27 & 1.24 & 1.20 & 1.06 & -0.06 & {$[-0.54]$} \\
\hline & & & & & & & & & & & Opt.-Pes. & -0.43 & {$[-2.90]$} \\
\hline \multicolumn{14}{|c|}{ Panel B: CAPM } \\
\hline Optimistic & $(\mathrm{n}=121)$ & 0.96 & 0.85 & 0.80 & 0.77 & 0.76 & 0.73 & 0.71 & 0.66 & 0.60 & 0.48 & -0.49 & {$[-6.26]$} \\
\hline Mild & $(n=233)$ & 0.78 & 0.83 & 0.86 & 0.86 & 0.87 & 0.85 & 0.84 & 0.82 & 0.77 & 0.62 & -0.17 & {$[-1.83]$} \\
\hline \multirow[t]{2}{*}{ Pessimistic } & $(\mathrm{n}=91)$ & 0.37 & 0.59 & 0.63 & 0.65 & 0.67 & 0.65 & 0.65 & 0.60 & 0.53 & 0.33 & -0.04 & {$[-0.33]$} \\
\hline & & & & & & & & & & & Opt.-Pes. & -0.45 & {$[-3.12]$} \\
\hline \multicolumn{14}{|l|}{ Panel C: FF } \\
\hline Optimistic & $(n=121)$ & 0.60 & 0.47 & 0.42 & 0.41 & 0.41 & 0.39 & 0.38 & 0.35 & 0.31 & 0.21 & -0.38 & {$[-4.34]$} \\
\hline Mild & $(n=233)$ & 0.36 & 0.42 & 0.48 & 0.49 & 0.52 & 0.51 & 0.52 & 0.51 & 0.48 & 0.37 & 0.01 & {$[0.14]$} \\
\hline \multirow[t]{2}{*}{ Pessimistic } & $(n=91)$ & 0.10 & 0.29 & 0.33 & 0.36 & 0.39 & 0.38 & 0.40 & 0.37 & 0.33 & 0.22 & 0.13 & {$[1.13]$} \\
\hline & & & & & & & & & & & Opt.-Pes. & -0.51 & {$[-3.58]$} \\
\hline
\end{tabular}

